\title{
Protective effect of linseed oil varnish on archaeological wood treated with alum
}

Jeannette Jacqueline Lucejko ${ }^{a}$, , Jacopo La Nasa ${ }^{a}$, Caitlin M. A. McQueen ${ }^{b}$, Susan Braovac ${ }^{b}$, Maria Perla Colombini ${ }^{\mathrm{a}, \mathrm{c}}$, Francesca Modugno $^{\mathrm{a}}$

aDepartment of Chemistry and Industrial Chemistry, University of Pisa, via G. Moruzzi 13, I-56127 Pisa, Italy

jeannette.lucejko@unipi.it, jacopo.lanasa@for.unipi.it, maria.perla.colombini@unipi.it, francesca.modugno@unipi.it,

${ }^{b}$ Department of Collection Management, Museum of Cultural History, University of Oslo, Postbox 6762 St. Olavs plass, 0130 Oslo, Norway

caitlin.mcqueen@khm.uio.no,susan.braovac@khm.uio.no

${ }^{c}$ Institute for the Conservation and Promotion of Cultural Heritage (ICVBC), National Research Council, via Madonna del Piano 10, I- 50019, Sesto Fiorentino, Florence, Italy

*Correspondence should be addressed to: Jeannette Jacqueline Lucejko, Department of Chemistry and Industrial Chemistry, University of Pisa, Via G. Moruzzi 13, I-50127 Pisa, Italy, email jlucejko@gmail.com tel. +39 050 2219258, fax +39 0502219260

\section{Abstract}

The Viking Age wooden artefacts recovered in the early 1900s from the Oseberg mound (Norway) and treated with alum, are today highly degraded. This is due to the effects of the alum-treatment and the reactivity of alum and alum-derived salts [1]. Some of the artefacts from the Oseberg collection that were treated with alum were also coated with a drying oil: boiled linseed oil. These artefacts appear to be better preserved with respect to those not treated with linseed oil.

In order to assess the effect of linseed oil on wood preservation, an alum-treated archaeological wood fragment from the Oseberg collection treated with linseed oil was investigated by three analytical techniques: gas chromatography coupled with mass spectrometry (GC/MS), pyrolysisgas chromatography/mass spectrometry (Py-GC/MS) and high-performance liquid chromatography coupled to electrospray ionisation and quadrupole time-of-flight mass spectrometry (HPLC-ESI-QToF). These techniques provided important information on the molecular composition and state of preservation of both archaeological wood and aged linseed oil.

Py(HMDS)-GC/MS was applied to assess the state of preservation of the main wood components, lignin and polysaccharides, in the presence of linseed oil and alum treatments. GC/MS and HPLCESI-Q-ToF were used to perform lipid characterization and to investigate the lipid degradation and oxidation processes. X-ray diffraction (XRD), Fourier transform infrared spectroscopy (FTIR) and 
elemental analysis by scanning electron microscopy coupled with energy dispersive X-ray spectroscopy (SEM-EDS) were performed to give information on the corresponding inorganic components, particularly the composition and distribution of the alum.

Samples taken at different depths from the surface of the archaeological wood fragment were analysed and compared. The results showed that, although the wood was highly depleted of carbohydrates, it was better preserved than previously analysed Oseberg artefacts not treated with linseed oil. Results from GC/MS and HPLC-ESI-Q-ToF suggested that the linseed oil played a mitigating role in terms of wood degradation. The behaviour of the lipid material, which was more oxidized on the wood surface than in the core, was the opposite to that usually encountered in archaeological wood, suggesting a selective oxidation of the oil.

This unusual pattern of wood degradation was not mirrored by the inorganic components: alum was found to be more abundant at the surface of the fragment than at depth, as would be expected, but no decomposition products were found. However, the alum appeared to mainly consist of ammonium salt, rather than the potassium alum documented as the treatment material for the Oseberg artefacts.

Key words: Oseberg archaeological wood, linseed oil, alum, Py-GC/MS, HPLC-ESI-Q-ToF, XRD

\section{Introduction}

The Oseberg Viking burial mound was discovered in 1903 near Tønsberg, Norway, and was dated to 834 AD [1]. The many archaeological objects recovered from the site included a Viking ship, numerous wooden and metal artefacts, textiles and remains of sacrificed animals, used as offerings to the two buried women. A selection of the find is exhibited at the Viking Ship Museum in Oslo, where visitors can have a glimpse of life in the Viking Age, and as well as the wood-working technology and wood-carving achievements [2].

The waterlogged wooden objects underwent different conservation processes depending on their condition upon excavation. The best preserved artefacts, made of oak (Quercus L.) (used, for example, for the hull of the Oseberg ship), ash (Fraxinus L.), pine (Pinus L.) and yew (Taxus L.) woods were mainly air-dried, while the highly deteriorated objects, mainly made of diffuse porous hardwoods such as maple (Acer L.) and birch (Betula L.), were treated with alum $\left(\mathrm{KAl}\left(\mathrm{SO}_{4}\right)_{2} \cdot 12 \mathrm{H}_{2} \mathrm{O}\right)$ [3]. This method consisted of immersing the waterlogged wooden fragments for up to 36 hours in a concentrated solution of alum, which was heated to $90^{\circ} \mathrm{C}$ to increase the salt's solubility. Alum penetrated into the surface of the wood, replacing the existing water and, on cooling, re-crystallized to give a physical support to the wood structure and reduce shrinkage during drying [4]. The concentrated alum solution at $90^{\circ} \mathrm{C}$ achieve $\mathrm{pH} 2$ after approximately three hours. This means that the wood was exposed to $\mathrm{pH} 2$ for approximately 33 hours for treatment 
times of 36 hours [5]. In accordance with Lange N. A. the solubility of potassium alum in $100 \mathrm{~g}$ of water at $90^{\circ} \mathrm{C}$ is $109 \mathrm{~g}$ [6].

Today many of the wooden objects treated with alum are in a poor state of conservation, mainly due to the fact that the alum treatment releases sulphuric acid when heated, according to the reaction:

$3 \mathrm{KAI}\left(\mathrm{SO}_{4}\right)_{2}+6 \mathrm{H}_{2} \mathrm{O} \rightarrow \mathrm{KAl}_{3}\left(\mathrm{SO}_{4}\right)_{2}(\mathrm{OH})_{6} \downarrow+\mathrm{K}_{2} \mathrm{SO}_{4}(\mathrm{aq})+3 \mathrm{H}_{2} \mathrm{SO}_{4}(\mathrm{aq})[7]$

This reaction has contributed to the objects' high acidity $(\mathrm{pH} \leq 2)$. Several studies have demonstrated that the presence of sulphur compounds in consolidated archaeological wood is related to degradation phenomena, that are far to be solved at the present state of the art [8, 9].

Previous studies performed by Py-GC/MS have shown that the chemical composition of the Oseberg alum-treated wood is very different from sound wood as well as from examples of archaeological wood not treated with alum [10-12]. The Oseberg alum treated wood has undergone a dramatic reduction in polysaccharides (cellulose and hemicelluloses), relative to lignin, as shown by the ratio of holocellulose over lignin content $(H / L$ index). In different types of sound wood, the $\mathrm{H} / \mathrm{L}$ index varies from 1.7 to 3.7. In the Oseberg wood that was not treated with alum, the $H / L$ index varies between 0.2 and 0.5 , due to the preferential decomposition of polysaccharides during burial and natural ageing [10].

In the Oseberg wood treated with alum, the $\mathrm{H} / \mathrm{L}$ index has values even below 0.1 , highlighting the almost complete loss of the polysaccharide components [10]. In addition, in the alum-treated wood, the lignin biopolymer has undergone oxidation to an extent never observed in other examples of archaeological wood [10, 11]. Studies of the correlation between $\mathrm{H} / \mathrm{L}$ ratios and inorganic content have suggested a direct relationship between wood degradation and the concentration of alumrelated elements $(\mathrm{Al}, \mathrm{K}, \mathrm{S})[10,11]$. However, many questions remain regarding the degradation processes occurring in treated archaeological wooden objects, as they are linked to complex interactions between organic and inorganic materials.

Many of the Oseberg wooden objects had also been treated with both alum and boiled linseed oil. Figure 1 shows a typical example of the distribution of both the alum salt and the linseed oil at the cellular level, in a sample taken from the surface of an Oseberg object. The drying oil, applied after the fragment had been air-dried to constant weight, improved its resilience, as the alum method resulted in wood that was as 'brittle as glass' [13]. The first applications of linseed oil were thinned with turpentine, with subsequent applications having an increasingly greater oil concentration. For smaller objects, linseed oil was applied by brush or by immersion until it was saturated. For larger objects, holes were drilled to improve the penetration [14]. In many cases, however, the oil did not completely penetrate the fragment. Linseed oil treated artefacts appear to be better preserved than those not treated with linseed oil. The consolidating effect of linseed oil probably also ensured the survival of the finely carved surfaces, a feature of many of the Oseberg wooden objects. 


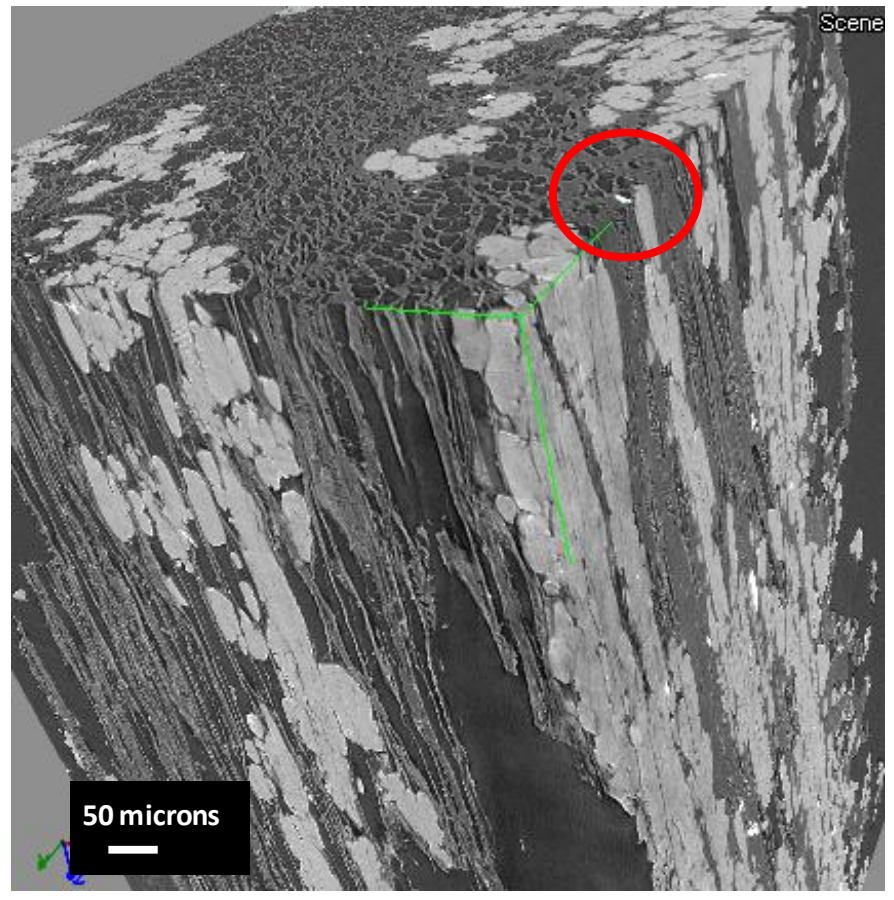

Figure 1 X-ray tomographic image showing the typical distribution of alum and linseed oil in a surface sample of one of the Oseberg objects. Alum salts are white/light grey. The linseed oil, which is indistinguishable from the wood fabric, coats fibres and encapsulates alum crystals in most regions. The red circle highlights an area where the linseed oil fills several wood cells. The bar shows 50 microns. Image taken at the TOMCAT beamline, Paul Scherrer Institute, Switzerland.

Linseed oil is a siccative oil characterised by the presence of highly polyunsaturated triacylglycerols (TAGs), Figure 2. Linolenic acid (octatrienoic) and linoleic acid (octadienoic), account for more than $65 \%$ of the total composition of fatty acids [15, 16]. Free fatty acids (FFAs) are generally present in a portion of $0.5-2 \%$ of the total weight, with an average composition related to the constituents of the TAGs. The amount of free fatty acids can increase as a result of the hydrolysis of the ester bonds of triacylglycerols.

Upon curing and ageing, the chemical composition of drying oils significantly changes. Autooxidation radical reactions lead to cross-linking processes involving the fatty acid (FA) portion of TAGs, resulting in the formation of a high molecular weight polymer network. Recombination of the radical species leads to the termination of the radical reaction process $[15,16]$.

One of the initial effects of the ageing process of a drying oil is the decrease in the degree of unsaturation and in the number of extractable triglycerides $[17,18]$. The amount of free fatty acids can increase with the increasing degree of hydrolysis during ageing. During hydrolysis, the concentration of diglycerides and monoglycerides reaches a maximum, which is then followed by a slow decrease, since the compounds undergo further hydrolysis, and produce glycerol and free fatty acids. Some reactions taking place during the curing lead to bond scission, with the consequent formation of low molecular weight degradation products, $\alpha, \omega$-dicarboxylic acids, with azelaic (nonanedioic) as the most abundant. 


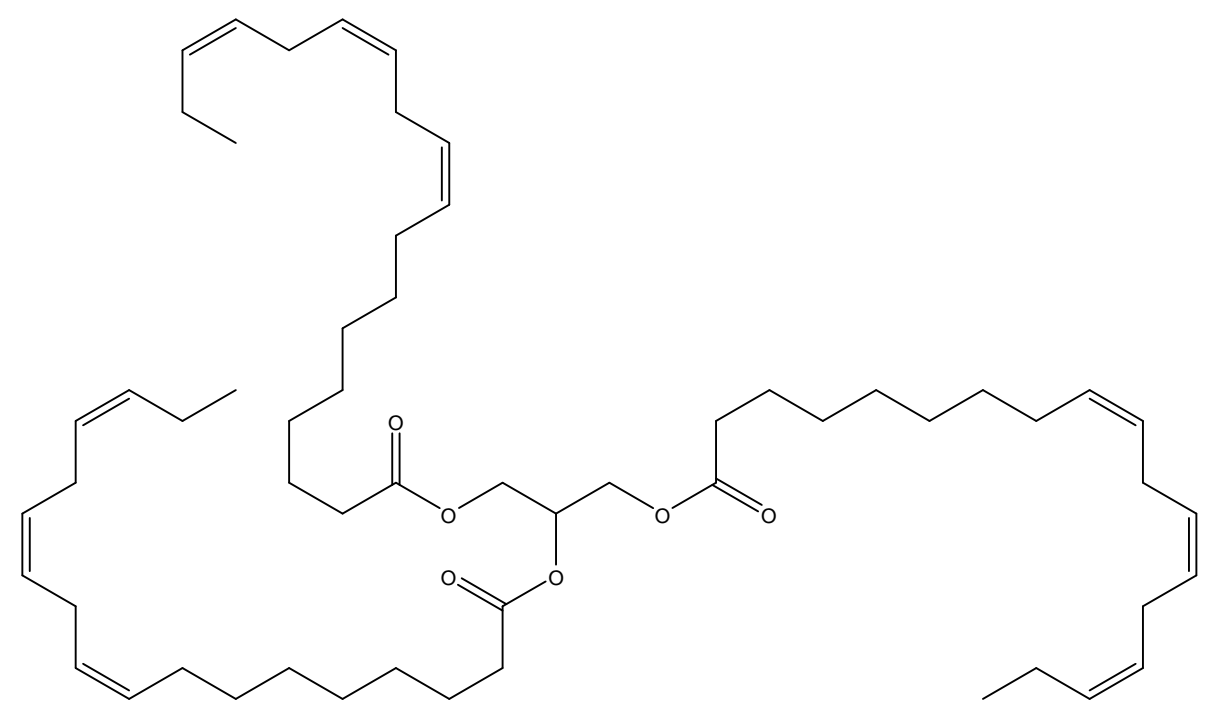

Figure 2 Trilinolenin, a triglyceride molecule with three linolenyl acyl substituents, which is characteristic of linseed oil.

The carboxylic groups released from the network as a consequence of the hydrolysis of triglycerides and of the oxidative cleavage of unsaturated fatty acids can react with cations to form metal soaps. This phenomenon has been described in paintings, where cations are present as pigments; for example, the formation of lead soaps by reaction with certain lead pigments in paintings is well known [19].

This work investigates Oseberg alum treated wood coated with linseed oil in order to assess the effect of its presence on wood preservation. A series of samples taken at different depths from the surface of one fragment (Figure 3) were analysed by various analytical techniques. This provided information on the molecular composition and state of preservation of both the archaeological wood and the aged linseed oil.

Pyrolysis-gas chromatography/mass spectrometry (Py-GC/MS) was applied to assess the state of preservation of the main wood components in the presence of linseed oil and the alum treatment. Gas chromatography coupled with mass spectrometry (GC/MS) and high-performance liquid chromatography coupled with electrospray ionisation and quadrupole time-of-flight mass spectrometry (HPLC-ESI-Q-ToF) [20] were used to perform the lipid characterization and to investigate lipid degradation and oxidation processes. Inorganic components of analysed material were also investigated by X-ray diffraction (XRD), scanning electron microscopy with energydispersive X-ray spectroscopy (SEM-EDS), and Fourier transform infrared spectroscopy (FTIR). We hope that this knowledge will contribute to the ongoing development of retreatment strategies for the long-term preservation of the artefacts.

\section{Materials and methods}

\subsection{Samples}


The investigation was performed on an archaeological wood fragment, C55000/207 (weight about $30 \mathrm{~g}$ ), from the Oseberg find. The fragment had been treated with alum and linseed oil (Figure 3).

Preliminary microscopic examination at a lower magnification indicated that the artefact is made of a diffuse porous hardwood. Detailed information on the origin of the wood fragments (sapwood or heartwood) was not available. The degree of degradation prevented a more specific identification of the wood genus. For this reason a typical diffuse porous wood, alder (alnus spp.), was used as a reference for Py(HMDS)-GC/MS, GC-MS, and HPLC-ESI-Q-ToF analyses.

The archaeological wood fragment C55000/207 was divided into four sections, in order to evaluate the chemical composition at different depths from the surface (Figure 3c).

These four sections were analyzed by:

- $\quad$ analytical pyrolysis coupled with gas chromatography and mass spectrometry (Py(HMDS)$\mathrm{GC} / \mathrm{MS}$ ) to evaluate the state of preservation of the main wood components;

- $\quad$ gas chromatography coupled with mass spectrometry (GC/MS) to investigate the profile of fatty acids and degradation products of the oil after saponification;

- high-performance liquid chromatography coupled with electrospray ionisation and quadrupole time-of-flight mass spectrometry (HPLC-ESI-Q-ToF) to investigate the profile of triglycerides and oxidized glycerides.

Additional samples from the outer surface (207-outer) and inner core (207-inner) were taken for analyse by SEM-EDS and XRD spectroscopy to gain information on the nature and distribution of inorganic components.

The samples are described in Table 1.

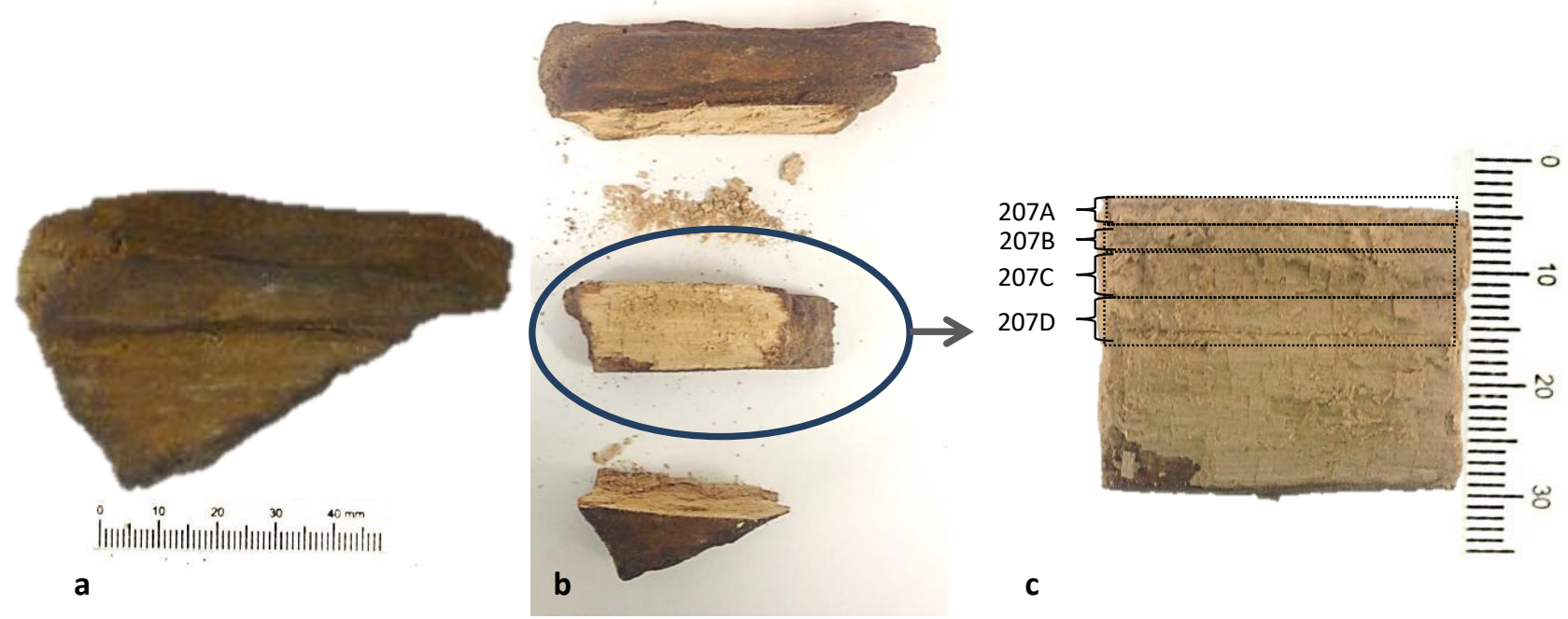

Figure 3 The alum and linseed oil treated fragment, whole (a) and cut into three pieces (b), which also highlights that the linseed oil (dark part) did not penetrate the wood fully (light part). The middle piece in (b) was sampled for our analyses. Photo $\mathrm{c}$ ) shows the depths from the surface from which samples were taken for the wood and linseed oil analyses. Samples for inorganic analyses were taken from the surface and from the core only. 
Table 1 Description of samples of Oseberg wood treated with alum and linseed oil

\begin{tabular}{|l|l|l|l|}
\hline Sample & Weight & Depth from the surface & Analysis \\
\hline $207 \mathrm{~A}$ & $0.4 \mathrm{~g}$ & $\begin{array}{l}\text { Sample taken from the surface } \\
\text { of fragment C55000/207 (0-1 } \\
\mathrm{mm})\end{array}$ & Wood and lipids \\
\hline $207 \mathrm{~B}$ & $0.5 \mathrm{~g}$ & $\begin{array}{l}\text { Sample taken from 1-2 mm } \\
\text { below the surface of fragment } \\
\text { C55000/207 }\end{array}$ & Wood and lipids \\
\hline $207 \mathrm{C}$ & $0.7 \mathrm{~g}$ & $\begin{array}{l}\text { Sample taken from 2-4 mm } \\
\text { below the surface of fragment } \\
\text { C55000/207 }\end{array}$ & Wood and lipids \\
\hline $207 \mathrm{D}$ & $0.7 \mathrm{~g}$ & $\begin{array}{l}\text { Sample taken from the core of } \\
\text { fragment C55000/207 }\end{array}$ & Wood and lipids \\
\hline 207 -inner & $\begin{array}{l}\text { Sample taken from core of } \\
\text { fragment C55000/207 }\end{array}$ & $\begin{array}{l}\text { Inorganic } \\
\text { compounds and } \\
\text { elements }\end{array}$ \\
\hline 207 -outer & $\begin{array}{l}\text { Sample taken from surface of } \\
\text { fragment C55000/207 }\end{array}$ & $\begin{array}{l}\text { Inorganic } \\
\text { compounds and } \\
\text { elements }\end{array}$ \\
\hline $\begin{array}{l}\text { Reference sound wood } \\
\text { sample }\end{array}$ & Alder (alnus, spp.) & Wood and lipids \\
\hline
\end{tabular}

\section{2. $\mathrm{Py}(\mathrm{HMDS})-\mathrm{GC} / \mathrm{MS}$}

Analytical pyrolysis was performed using 1,1,1,3,3,3-hexamethyldisilazane (HMDS, chemical purity 99.9\%, Sigma Aldrich Inc., USA) as a silylation agent for the in situ thermally-assisted derivatisation of pyrolysis products. The instrumentation consisted of a micro-furnace Multi-Shot Pyrolyzer EGA/Py-3030D (Frontier Lab) coupled to a gas chromatograph 6890 Agilent Technologies (USA) equipped with an HP-5MS fused silica capillary column (stationary phase $5 \%$ diphenyl - $95 \%$ dimethyl-polysiloxane, $30 \mathrm{~m} \times 0.25 \mathrm{~mm}$ i.d., Hewlett Packard, USA) and with a deactivated silica pre-column ( $2 \mathrm{~m} \times 0.32 \mathrm{~mm}$ i.d., Agilent J\&W, USA). The GC was coupled with an Agilent 5973 Mass Selective Detector operating in electron impact mode (EI) at $70 \mathrm{eV}$. The pyrolysis temperature was $550^{\circ} \mathrm{C}$ and interface temperature was $250{ }^{\circ} \mathrm{C}$. Approximately $100 \mu \mathrm{g}$ of sample and $5 \mu \mathrm{L}$ HMDS were inserted into the platinum cup. Before analysis, all the samples were oven-dried for $24 \mathrm{~h}$ at $40-50{ }^{\circ} \mathrm{C}$ to remove residual water (alum salts were not removed). Samples were analysed in triplicate.

The identification and integration of peaks derived from lignin and holocellulose products was performed using AMDIS software, which helps to deconvolute and integrate chromatographic peaks on the basis of their mass spectra even when there are overlapping signals. Deconvolution software is particularly useful in this case because pyrolysis chromatograms from this sample contain peaks deriving from both wood and linseed oil. Details regarding the pyrolysis products identified are presented in [10]. The relative content of wood components was obtained by integrating selected chromatographic peak areas. The areas of the peaks were then normalised 
and expressed as percentages of the sum of all the identified pyrolysis products (a total of 117 compounds) $[10,11]$. The technique achieves a relative standard deviation of $7.3 \%$ [21].

\subsection{GC-MS for the identification of the fatty acid profile}

For the GC/MS analysis of samples, 2-3 $\mathrm{mg}$ of the sample were subjected to microwave assisted saponification (power $200 \mathrm{~W}$ ) with $300 \mu \mathrm{L}$ of $10 \% \mathrm{KOH}$ in $\mathrm{EtOH}$ (by weight) at $80{ }^{\circ} \mathrm{C}$ for $60 \mathrm{~min}$. In order to maximize the extraction yield, two solvents were used: the neutral compounds were extracted with $n$-hexane $(400 \mu \mathrm{L}$, three times); the residual solution was acidified with hydrochloric acid $(6 \mathrm{M})$ and then carboxylic acids were extracted with diethyl ether ( $400 \mu \mathrm{L}$, three times). The two extracts (neutral + acidic fraction) were combined, evaporated to dryness under nitrogen stream, and subjected to derivatization with $20 \mu \mathrm{L}$ of $\mathrm{N}, \mathrm{O}$-bistrimethylsilyltrifluoroacetamide (BSTFA), $150 \mu \mathrm{L}$ of iso-octane and $5 \mu \mathrm{L}$ of tridecanoic acid solution (IS2) at $60{ }^{\circ} \mathrm{C}$ for $30 \mathrm{~min} .5 \mu \mathrm{L}$ of hexadecane solution (IS1) were added just before injection.

GC/MS instrumentation consisted of an Agilent Technologies 6890N Gas Chromatograph coupled with a 5975 Mass Selective Detector single-quadrupole mass spectrometer. Samples were injected in splitless mode at $280^{\circ} \mathrm{C}$. GC separation was performed on a fused silica capillary column HP. $5 \mathrm{MS}$ (J\&W Scientific, Agilent Technologies, stationary phase 5\% diphenyl-95\% dimethylpolysiloxane, $30 \mathrm{~m}$ length, $0.25 \mathrm{~mm}$ i.d., $0.25 \mu \mathrm{m}$ film thickness). Chromatographic conditions were: initial temperature $80^{\circ} \mathrm{C}, 2 \mathrm{~min}$ isothermal, $10^{\circ} \mathrm{C} / \mathrm{min}$ up to $200^{\circ} \mathrm{C}, 4 \mathrm{~min}$ isothermal for the separation of unsaturated $\mathrm{C} 18$ fatty acids and their isomers, $6^{\circ} \mathrm{C} / \mathrm{min}$ up to $280^{\circ} \mathrm{C}, 40$ minutes isothermal. The helium (purity 99.9995\%) gas was set in constant flow mode at $1.2 \mathrm{~mL} / \mathrm{min}$. MS parameters: electron impact ionization $(\mathrm{EI}, 70 \mathrm{eV})$ in positive mode; ion source temperature $230^{\circ} \mathrm{C}$; scan range $50-700 \mathrm{~m} / \mathrm{z}$; interface temperature $280^{\circ} \mathrm{C}$. The injection volume was $2 \mu \mathrm{L}$.

The GC/MS quantitative analysis was performed using calibration curves calculated on the basis of selected ion monitoring (SIM) chromatograms: the selected ions for the SIM acquisition were: lauric acid m/z 117, 257; suberic acid m/z 169, 303; azelaic acid m/z 149, 317; myristic acid m/z 117, 285; sebacic acid m/z 149, 331; palmitic acid m/z 117, 313; oleic acid m/z 117, 339; stearic acid $\mathrm{m} / \mathrm{z} 117,341$.

The quantitative determination of aliphatic mono- and dicarboxylic acids was performed using standard solutions, building calibration curves, and evaluating daily recoveries. Running blanks of the procedure highlighted a low level of contamination. The detection limit (LOD) and the quantitation limit (LOQ) of fatty and dicarboxylic acids were calculated. At a statistical significance level of 0.05 , the LODs and LOQs obtained of the proteinaceous, glycerolipids and saccharide materials were as follows: LOD: $0.3 \mu \mathrm{g}$; LOQ: $0.7 \mu \mathrm{g}$. 


\subsection{High-performance liquid chromatography coupled to electrospray ionisation and quadrupole time-of-flight mass spectrometry for the identification of the triglyceride profile of lipids}

For the HPLC-ESI-Q-ToF analyses, 2-3 mg of each sample was subjected to microwave assisted extraction assisted by microwaves in a microwave oven Ethos One (Milestone, U.S.A.) (power 600 $W$ ), with $300 \mu \mathrm{L}$ of a chloroform-hexane $(3: 2)$ mixture at $80^{\circ} \mathrm{C}$ for $25 \mathrm{~min}$. The extracts were dried under a nitrogen stream, diluted with $600 \mu \mathrm{L}$ of elution mixture, and filtered on a $0.45 \mu \mathrm{m}$ PTFE filter (Grace Davison Discovery Sciences, U.S.A.) just before injection [22, 23].

HPLC-ESI-Q-ToF analyses were carried out using a 1200 Infinity HPLC, coupled with a Quadrupole-Time of Flight tandem mass spectrometer 6530 Infinity Q-ToF detector by a Jet Stream ESI interface(Agilent Technologies, U.S.A.).

The HPLC conditions were: Poroshell $120 \mathrm{EC}-\mathrm{C} 18$ column $(3.0 \mathrm{~mm} \times 50 \mathrm{~mm}, 2.7 \mu \mathrm{m}$ particle size) with a Zorbax eclipse plus C-18 guard column $(4.6 \mathrm{~mm} \times 12.5 \mathrm{~mm}, 5 \mu \mathrm{m}$ particle size); a flow rate of $0.3 \mathrm{~mL} / \mathrm{min}$, an injection volume of $1 \mu \mathrm{L}$ and a column temperature of $45^{\circ} \mathrm{C}$. Separation was achieved using a gradient of methanol (eluent $\mathrm{A}$ ) and iso-propanol (eluent B). The elution gradient was programmed as follows: $90 \%$ A for $5 \mathrm{~min}$, followed by a linear gradient to $90 \%$ B in $25 \mathrm{~min}$, then held for $5 \mathrm{~min}$. Re-equilibration time for each analysis was $10 \mathrm{~min}$. The ESI operating conditions were: drying gas $\left(\mathrm{N}_{2}\right.$, purity $\left.>98 \%\right)$ : $350^{\circ} \mathrm{C}$ and $10 \mathrm{~L} / \mathrm{min}$; capillary voltage $4.5 \mathrm{kV}$; nebulizer gas $35 \mathrm{psig}$; sheath gas $\left(\mathrm{N}_{2}\right.$, purity $\left.>98 \%\right): 375^{\circ} \mathrm{C}$ and $11 \mathrm{~L} / \mathrm{min}$. High resolution $\mathrm{MS}$ and MS/MS spectra were acquired in positive mode in the range 100-1700 m/z. The fragmentor was kept at $200 \mathrm{~V}$, nozzle voltage $1000 \mathrm{~V}$, skimmer $65 \mathrm{~V}$, octapole RF $750 \mathrm{~V}$, and the collision energy for the MS/MS experiments was set at $50 \mathrm{~V}$. The collision gas was nitrogen (purity 99.999\%). The data were collected by auto MS/MS acquisition with an MS scan rate of 1.03 spectra/s and an MS/MS scan rate of 1.05 spectra/s; only one precursor was acquired per cycle (relative threshold 0.010\%) [24-26].

HPLC-EIS-Q-ToF quantitation, relative abundances were calculated on the basis of extract ion chromatograms, considering the isotopic distribution of the molecular species, and normalized to $100 \%$.

\subsection{XRD}

X-ray diffraction analysis was carried out using a PANalytical diffractometer Empyrean Series 2 with radiation CuKa1 $=1.54 \AA$, operating at $45 \mathrm{kV}, 40 \mathrm{~mA}, 2 \theta$ range $5-80^{\circ}$ step size $0.03^{\circ}$, time per step $1000 \mathrm{~s}$ or $5000 \mathrm{~s}$, rotation time $2.0 \mathrm{~s}$, equipped with a PIXcel ${ }^{1 \mathrm{D}}$-Medipix3 RTMS detector, and High Score data acquisition and interpretation software. A zero background sample holder was used. Crystalline phases were identified using the ICDD database. Samples were finely ground, and enough powder to cover the $1.5 \mathrm{~cm}$ diameter area of the sample holder was used. 


\subsection{SEM-EDS}

SEM-EDS analyses were performed using a FEI Quanta 450 Scanning Electron Microscope coupled with an Oxford X-Max ${ }^{\mathrm{N}} 50 \mathrm{~mm}^{2}$ detector, using low vacuum mode to avoid charging and a voltage of $20 \mathrm{kV}$. The other parameters (spot size, pressure, and working distance) were modified depending on the sample. For the SEM-EDS measurements, small amounts of powdered sample approximately $0.5 \mathrm{~mm}^{2}$ in area were scanned.

\subsection{FT-IR spectroscopy}

Spectra in attenuated total reflection (ATR) mode were recorded on a Thermo Fischer FTIR spectrometer (Nicolet iS50). 32 scans and $4 \mathrm{~cm}^{-1}$ resolution were adopted. The range was $4000-$ $400 \mathrm{~cm}^{-1}$. Enough finely ground sample to cover the $3 \mathrm{~mm}$ diameter area of the ATR crystal was used.

\section{Results}

\subsection{Analyses of organic components}

\subsubsection{Linseed oil characterisation}

Chemical analyses were performed to characterise aged lipids derived from the linseed oil used on the alum treated wood at different depths from the surface.

The characterization of lipids from linseed oil was carried out by two complementary approaches: the quantitative profile of fatty acids (FAs) was determined by GC/MS after saponification, extraction and derivatization, while the triglycerides (TAGs) were profiled using HPLC-ESI-Q-ToF analysis.

Generally, the FA profiles of aged drying oils are characterized by the ratio of the saturated acids, palmitic acid (hexadecanoic, C16:0) over stearic acid (octadecanoic, C18:0) which are the most abundant. On the other hand, unsaturated acids, such as linolenic acid (cis,cis,cis-9,12,15octadecatrienoic acid, C18:3), which are abundant in fresh linseed oil, are not detected after ageing since they tend to undergo oxidation and cross-linking processes which result in the formation of a polymeric fraction and oxidized species [15, 16].

In the GC/MS chromatogram obtained from the analysis of surface sample 207A (Figure 4), palmitic and stearic acids were the most abundant peaks, as expected.

In addition, a small amount of oleic acid, a monounsaturated fatty acid, was still present and the $\alpha, \omega$-dicarboxylic acids formed as products of oxidation, such as suberic ( $\alpha, \omega$-octanedioic acid), azelaic ( $\alpha, \omega$-nonanedioic acid) and sebacic ( $\alpha, \omega$-decanedioic acid) acids, were also observed. Dicarboxylic acids are not originally present in linseed oil, but they are formed during curing and 
ageing as a result of preferential oxidation and bond cleavage at the double bonds in the acylic chain $[15,16]$.



Figure 4 Selected ion monitoring (SIM) chromatographic profile of the fatty acid fraction of sample 207A taken 0-1 $\mathrm{mm}$ from the surface, after saponification and silylation of carboxylic moieties.

Qualitative comparison of the chromatographic profiles and quantitative analyses highlighted differences in the fatty acid profiles of linseed oil at different depths from the surface. Table 2 reports the relative amounts of fatty acids in the analysed samples, while Figure 5 shows the distribution of FAs in samples taken at different depths from the surface.

The organic extractable fraction of wood also contains glycerides and fatty acids, thus reference wood was also analysed to evaluate the contribution of wood to the fatty acid profile.

Table 2 Relative content of fatty acids in the analysed samples taken at different depths from the surface of fragment 207 and from untreated reference wood. P/S: ratio of the amounts of palmitic and stearic acids. $\Sigma$ Dic.\%: sum of the percentage amounts of dicarboxylic acids (suberic, azelaic and sebacic).

\begin{tabular}{|c|c|c|c|c|c|c|c|c|c|c|c|c|}
\hline \multirow[t]{2}{*}{ Samples } & 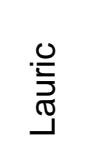 & $\begin{array}{l}\frac{0}{\bar{D}} \\
\frac{O}{J} \\
\mathscr{\omega}\end{array}$ & $\begin{array}{l}\frac{0}{N} \\
\frac{N}{N} \\
\frac{N}{\alpha}\end{array}$ & $\frac{.0}{\frac{0}{\tilde{n}}}$ & $\begin{array}{l}\frac{0}{D} \\
\mathbb{D} \\
\mathbb{D} \\
\mathscr{D}\end{array}$ & $\begin{array}{l}\stackrel{0}{\underline{\underline{E}}} \\
\frac{\vec{E}}{\widetilde{\sigma}} \\
\square\end{array}$ & $\frac{\frac{0}{\mathscr{\omega}}}{0}$ & 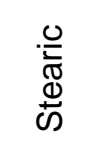 & \multirow[t]{2}{*}{$\begin{array}{l}\mu \mathrm{g} \text { in } \\
\text { sample }\end{array}$} & \multirow[t]{2}{*}{$\mathrm{ug} / \mathrm{g}$} & \multirow[t]{2}{*}{$\mathrm{P} / \mathrm{S}$} & \multirow[t]{2}{*}{$\Sigma$ Dic. $\%$} \\
\hline & \multicolumn{8}{|c|}{$\%$ in sample } & & & & \\
\hline $207 \mathrm{~A}(0-1 \mathrm{~mm})$ & 0.4 & 2.5 & 14.3 & 1.1 & 1.9 & 43.5 & 0.7 & 35.7 & 49.5 & 81.1 & 1.2 & 18.7 \\
\hline 207B (1-2 mm) & 0.5 & 2.2 & 18.5 & 0.8 & 0.9 & 33.8 & 8.9 & 34.3 & 7.9 & 11.3 & 1.0 & 21.7 \\
\hline $207 \mathrm{C}(2-4 \mathrm{~mm})$ & 0.7 & 0.9 & 7.9 & 1.1 & 0.4 & 33.7 & 26.7 & 28.4 & 7.9 & 10.3 & 1.2 & 9.3 \\
\hline 207D (core) & 0.8 & 0.3 & 7.0 & 1.3 & 0.2 & 32.1 & 30.8 & 27.5 & 6.0 & 7.7 & 1.2 & 7.6 \\
\hline sound alder & 1.8 & 0.1 & 11.2 & 2.4 & 0.3 & 34.8 & 6.5 & 42.9 & 2.5 & 3.3 & 0.8 & 11.6 \\
\hline
\end{tabular}

The relative contents of fatty acids determined in the untreated reference wood and in archaeological samples were significantly different: the palmitic/stearic ratios (P/S) were between 1 
and 1.2 for the samples from fragment 207 , as expected for linseed oil, and 0.8 in reference sound wood.

The total amount of fatty acids calculated in micrograms in the sample was much lower in reference sound wood $(2.5 \mu \mathrm{g})$ than in the wood samples taken from the surface that had been treated with drying oil $(49.5 \mu \mathrm{g})$. Also, the determined amount of fatty acids decreased from sample 207A (surface) to sample 207D (core), highlighting that the penetration of linseed oil was limited to the first $4 \mathrm{~mm}$ from the surface.

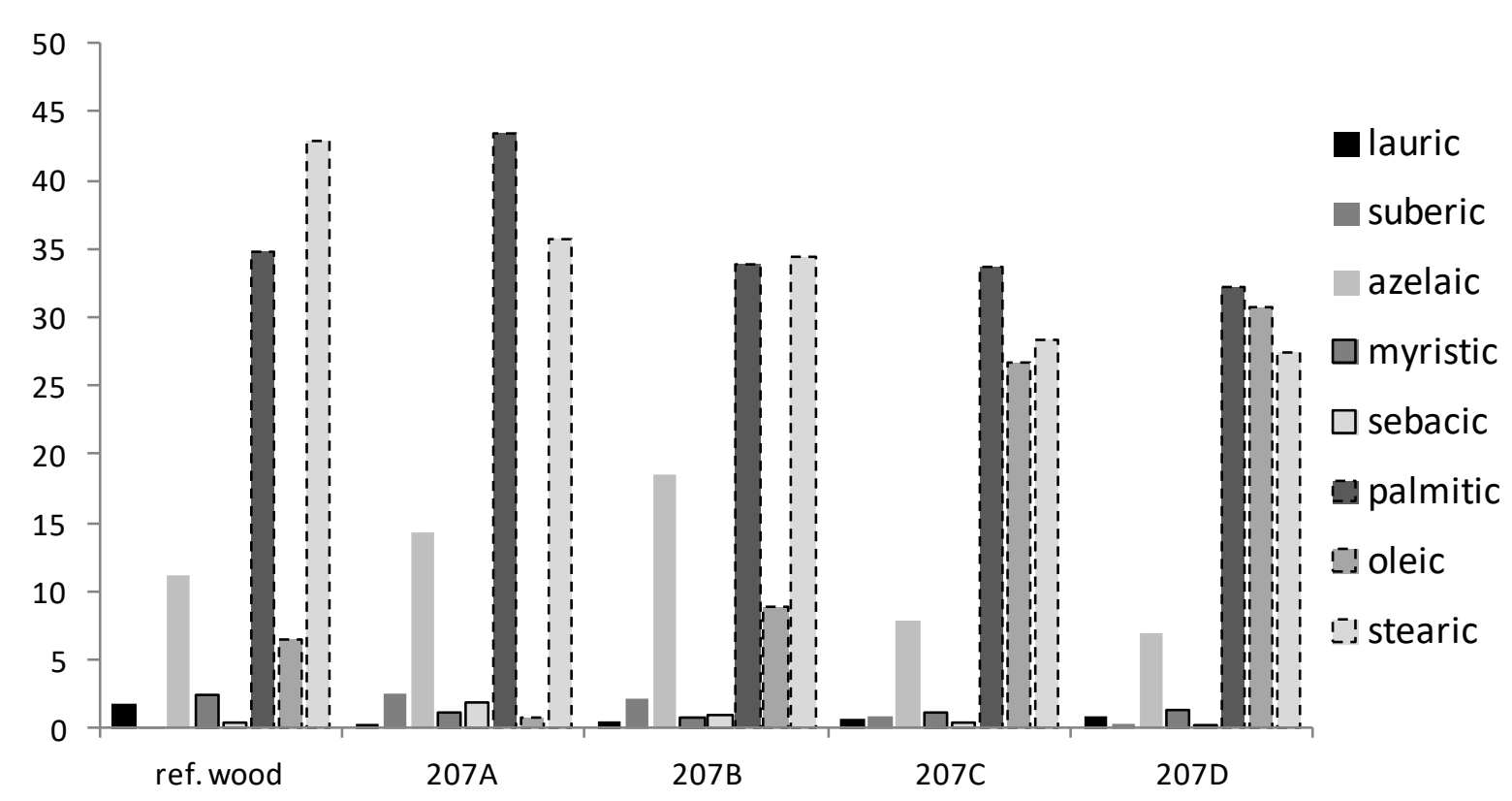

Figure 5 Distribution of fatty acids in samples taken at different depths of fragment 207 and reference sound wood.

The GC/MS analysis of samples taken between 2-4 mm from the surface (samples $207 \mathrm{C}$ and 207D) were characterised by a relatively higher amount of residual oleic acid than in the surface sample (207A), revealing that the oxidation of the unsaturated fatty acids was more prominent in the surface, as expected. The degree of oxidation at different depths was also highlighted by the different amounts of dicarboxylic acids (suberic, azelaic and sebacic acids): on the surface the sum of the relative amount of dicarboxylic acids ( $\Sigma$ Dic.\%) was around $20 \%$, while in the core 207D, it was less than $8 \%$ (Table 2). Thus, these oxidation products were more abundant in the first $2 \mathrm{~mm}$ (samples A and B).

Lipid analysis by GC/MS was complemented with the direct analysis of triacylglycerides (TAGs), without saponification, by means of high-performance liquid chromatography coupled with electrospray ionization and quadrupole time-of-flight mass spectrometry (HPLC-ESI-Q-ToF). Only free TAGs and their oxidation products can be extracted and analysed by HPLC, while the crosslinked fraction is not soluble and not characterised with common analytical techniques.

The TAG profile of fresh linseed oil was characterised by the presence of a high amount of triglycerides containing the triple unsaturated linolenic acid (C18:3), as well as high amounts of 
linoleic (C18:2) and oleic (C18:1) acids [24]. As previously mentioned, with ageing, unsaturated acyl chains undergo oxidation processes that modify the TAG profile. The TAG profiles of the samples collected from the surface (207A) and from the core (207D) of the fragment of archaeological wood treated with linseed oil are shown in Figure 6 and Figure 7, respectively .

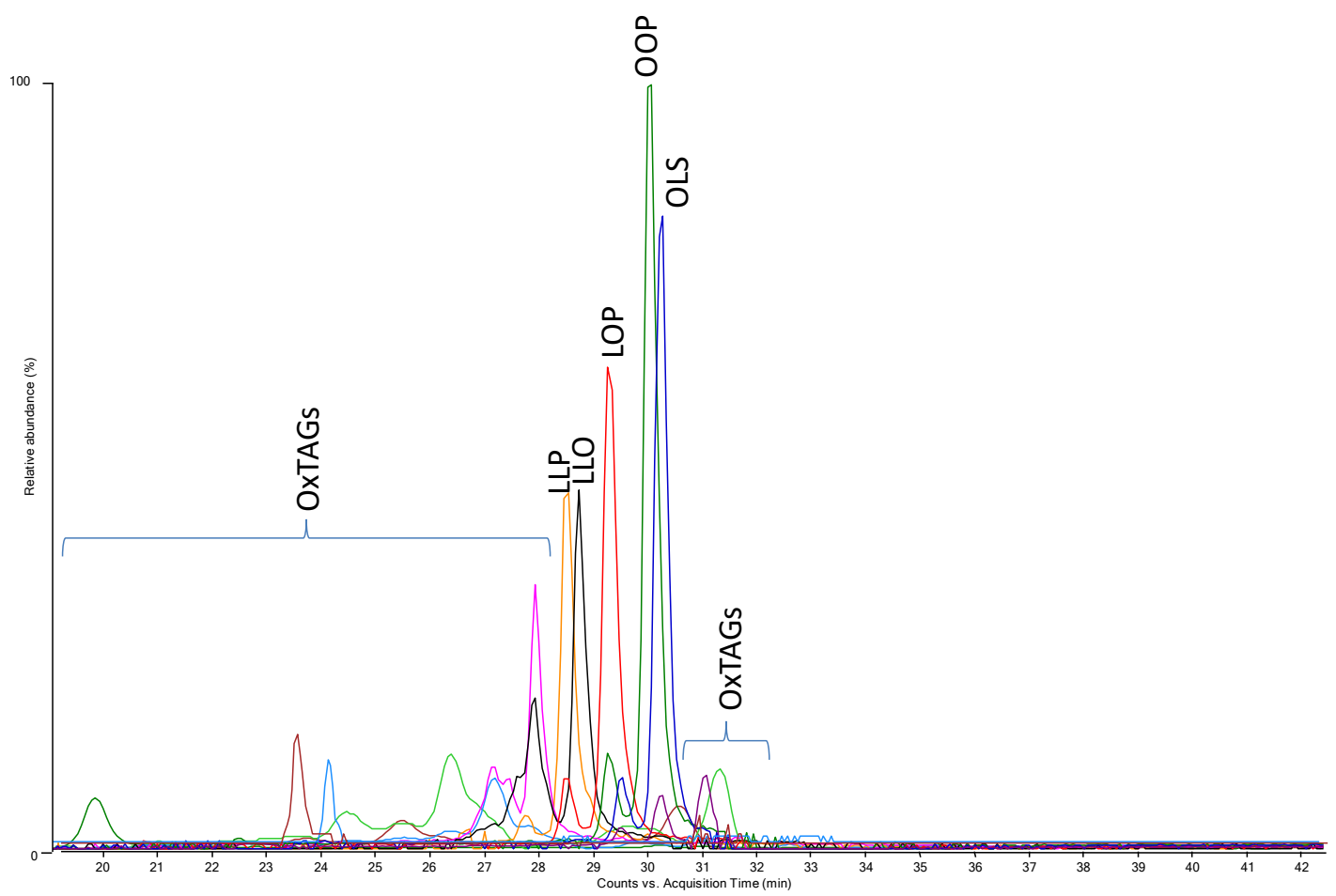

Figure 6 HPLC-ESI-Q-ToF extract ion chromatograms of sample 207A taken within 0-1 $\mathrm{mm}$ of the surface. L-(18:2) linoleic, O- (18:1) oleic ; P- (16:0) palmitic, S-(18:0) stearic, OxTAGs- oxidized triacylglycerides.

The HPLC TAG profiles of sample 207A taken from the surface were characterised by the presence of OOP, OLS and LOP as main triglycerides, which are characteristic of linseed oil. The TAG profile showed the presence of a substantial amount of oxidized triglycerides (OxTAGs) derived from an oxidation process involving the linolenyl acyl substituents in fresh linseed oil. The oxidised TAGs detected in the sample were characterised by double bonds in the acyl substituent no greater than one, producing the ions: $\mathrm{m} / \mathrm{z} 945.7 \quad\left(\mathrm{C}_{18, \mathrm{OH}} \mathrm{C}_{18, \mathrm{OH}} \mathrm{S}, \quad[\mathrm{M}+\mathrm{Na}]^{+}\right), \quad 917.7$ $\left(\mathrm{C}_{18: 1, \mathrm{OH}} \mathrm{C}_{18: 1, \mathrm{OH}} \mathrm{P},[\mathrm{M}+\mathrm{Na}]^{+}\right)$, and $897.7\left(\mathrm{C}_{18: 1, \mathrm{OH}} \mathrm{OP},[\mathrm{M}+\mathrm{Na}]^{+}\right)$. These results suggest that the oil in the surface of the sample was in an advanced oxidized state [27].

Comparing the triglyceride profile obtained in surface sample 207A with that obtained for core sample 207D (Figure 7), we found several surviving polyunsaturated TAGs, typical of fresh linseed oil. In particular, TAGs containing linoleic acid (9,12-octadecadienoic acid) were present, while TAGs containing linolenic acid (9,12,15-octadecatrienoic acid) were not detected in any of the four samples. The oxidation products detected in the core sample were characterised by a high number of residual double bonds (up to 2 ), in particular $\mathrm{m} / \mathrm{z} 937.7\left(\mathrm{C}_{18: 2, \mathrm{OH}} \mathrm{C}_{18: 2, \mathrm{OH}} \mathrm{S},[\mathrm{M}+\mathrm{Na}]^{+}\right), 909.7$ $\left(\mathrm{C}_{18: 2, \mathrm{OH}} \mathrm{C}_{18: 2, \mathrm{OH}} \mathrm{P},[\mathrm{M}+\mathrm{Na}]^{+}\right)$were the most abundant oxidized species detected.

Table 3 reports the triglycerides detected in the samples. 


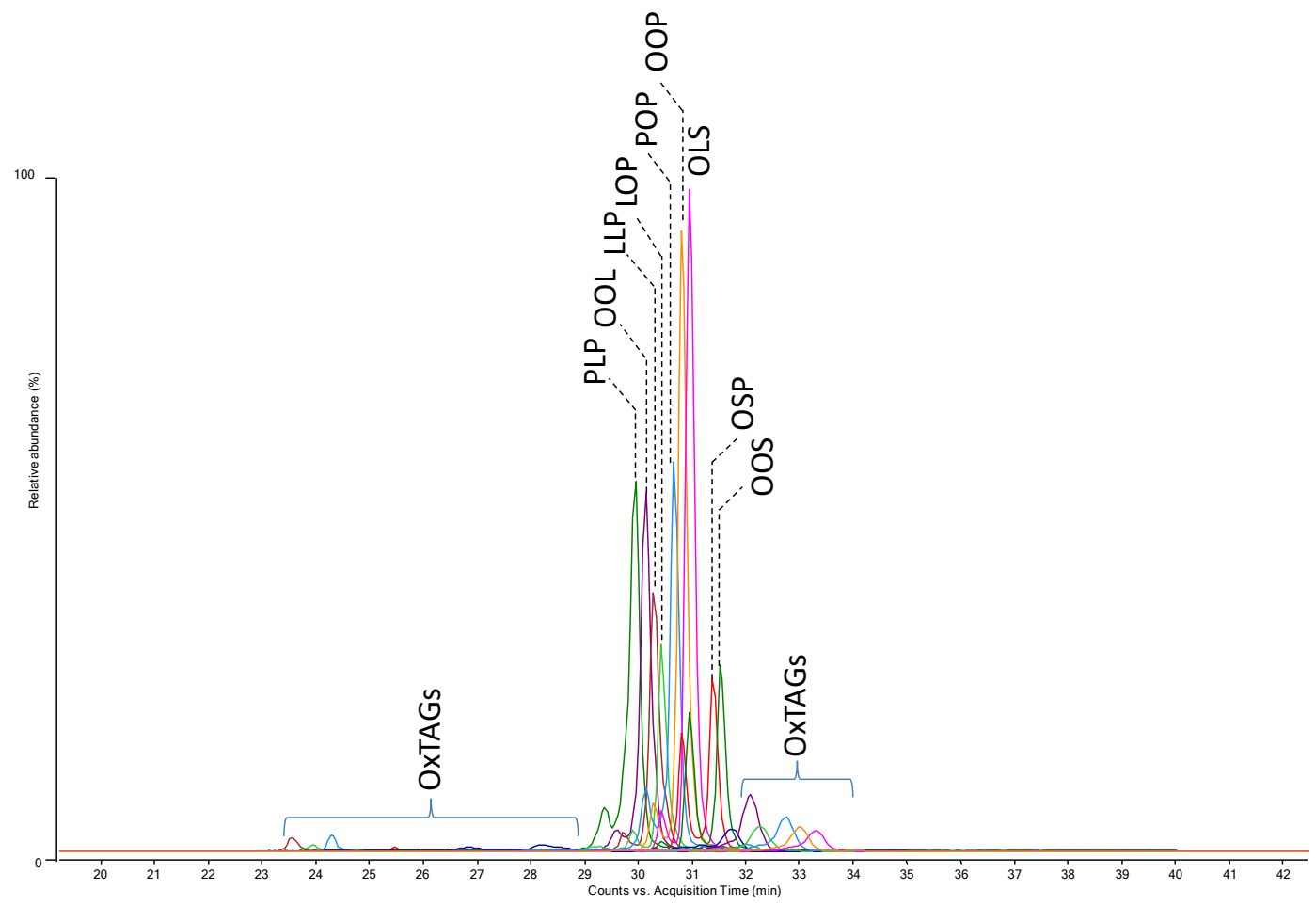

Figure 7 HPLC-ESI-Q-ToF extract ion chromatograms of sample 207D taken from the core of fragment 207. L-(18:2 ) linoleic, O- (18:1) oleic; P- (16:0) palmitic, S-(18:0) stearic, OxTAGs- oxidized triglycerides.

Table 3 Surviving TAGs and the main oxidized TAGs identified in surface (207A) and core (207D) samples from fragment 207

\begin{tabular}{|l|l|}
\hline 207A & 207D \\
\hline $\mathrm{C}_{18, \mathrm{OH}} \mathrm{C}_{18, \mathrm{OH}} \mathrm{S}^{*}$ & - \\
\hline $\mathrm{C}_{18: 1, \mathrm{OH}} \mathrm{C}_{18: 1, \mathrm{OH}} \mathrm{P}$ & - \\
\hline $\mathrm{C}_{18: 1, \mathrm{OH}} \mathrm{OP}$ & - \\
\hline- & $\mathrm{C}_{18: 2, \mathrm{OH}} \mathrm{C}_{18: 2, \mathrm{OH}} \mathrm{S}$ \\
\hline- & $\mathrm{C}_{18: 2, \mathrm{OH}} \mathrm{C}_{18: 2, \mathrm{OH}} \mathrm{P}$ \\
\hline- & $\mathrm{PLP}$ \\
\hline- & $\mathrm{OOL}$ \\
\hline LLP & LLP \\
\hline LLO & - \\
\hline LOP & LOP \\
\hline- & POP \\
\hline OOP & OOP \\
\hline OLS & OLS \\
\hline- & OSP \\
\hline- & OOS \\
\hline
\end{tabular}

Abbreviations: ${ }^{*} X: Y, O H: X X$-carbon atom numbers, $Y$ double bonds, hydroxyl group; ${ }^{*} L-(18: 2)$ linoleic, 0 - (18:1) oleic (unsaturated); $\boldsymbol{P}$ - (16:0) palmitic, $\boldsymbol{S}$-(18:0) stearic (saturated);

The overall interpretation of the TAG profiles and the GC/MS reveals that the lipid material in the core was less oxidised and less polymerised than that found on the surface. This behaviour is consistent with that expected for an adsorbed coating, and is related to the presence of oxygen and light, which are the main oxidation factors of drying oil. We also found that below the surface, the oxidation rate of the unsaturated acyl chains decreased. 


\subsubsection{Analysis of the wood components by Py(HMDS)-GC/MS}

The effect of linseed oil on the preservation of the wood components at different depths from the sample surface was assessed by comparing results from Py-GC/MS analyses, using in situ thermally assisted derivatization with HMDS. The chromatographic profiles obtained for the reference alder wood and for the Oseberg samples are shown in Figure 8.

Notable differences are evident between the reference sound wood and the archaeological wood treated with alum and linseed oil, as well as between the samples taken at different depths.

Although the pyrograms for archaeological wood samples appear qualitatively very similar, they differ in their proportion of lignin pyrolysis products, as discussed below. The most abundant pyrolysis products in the archaeological wood samples originated from the linseed oil (the most abundant peaks are labelled with an asterisk) (Figure 8). Of the pyrolysis products derived from the lignocellulosic polymers, the most abundant originated from the lignin, while the products from the polysaccharide (holocellulose) component were in very low abundances.

The most abundant lignin pyrolysis products were the monomers, synapyl and coniferyl alcohols together with syringaldehyde. Acidic lignin pyrolysis products such as p-hydroxybenzoic and syringic acids were also appreciably abundant. Corresponding guaiacyl compounds such as vanillin and vanillic acid were less abundant.

The ratio of relative contents of holocellulose $(H)$ over lignin $(L)$ is a parameter used for the assessment of the state of preservation of archaeological wood [28, 29]. The relative amounts of main wood components and the values of $\mathrm{H} / \mathrm{L}$ ratios are presented in Figure 9.

A relatively low amount $(8-20 \%$ ) of holocellulose pyrolysis products was observed in the archaeological alum-treated wood with respect to the sound wood sample where holocellulose accounted for about $66 \%$ of all selected chromatographic peak areas. This demonstrates an extensive loss of holocellulose in the archaeological wood.

When comparing results obtained for samples collected at different depths from the surface, the wood composition changed. In the surface (sample 207A), the $\mathrm{H} / \mathrm{L}$ ratio was higher $(0.20)$ than in the core (0.10). From the surface to the core, we observed a gradual decrease in $\mathrm{H} / \mathrm{L}$ index (Figure 9), indicating that the wood at the surface was better preserved than the wood in the core of the analysed fragment. This was rather unexpected given that, generally, the surface of an archaeological wood artifact, which is in contact with the environment, undergoes more evident degradation processes than the core.

The categorization of pyrolysis products enables the relative amounts of primary and secondary pyrolysis products to be evaluated, thus simplifying the understanding of alteration phenomena of polysaccharides [30]. Pyrolysis products derived from cellulose and hemicelluloses can be divided into five categories: furans, cyclopentenones, pyranones, hydroxybenzenes and anhydrosugars $[30,31]$. The most abundant category in sound wood is generally made up of cyclopentenones, in 
particular due to the formation of 3-hydroxy-2-hydroxymethyl-2-cyclopentenone (2TMS), and E-2,3dihydroxy-cyclopent-2-enone (2TMS). The second most abundant group is composed of anhydrosugars which are mainly represented by levoglucosan (1,6-anydro-beta-D-glucopyranose (3TMS)). For degraded wood, the polysaccharides formed during pyrolysis are mainly anhydrosugars. These compounds may be present in different trimethylsilyl (TMS) derivative forms: tri-TMS, di-TMS and mono-TMS. The efficacy of the derivatisation reaction between hydroxyl groups and HMDS can be affected by steric hindrance, which thus prevents HMDS from being combined with functionalities [32, 33]. More degraded polymer networks, which present a more open and incoherent structure, are more reactive towards silylation agents. Thus the relative amount of persilylated (tri-TMS) anhydrosugars is higher for samples in which carbohydrates are more degraded, indicating depolymerisation. The relative amounts of monosilylated, disilylated and persilylated anhydrosugars were calculated, and are shown in Figure 10. 


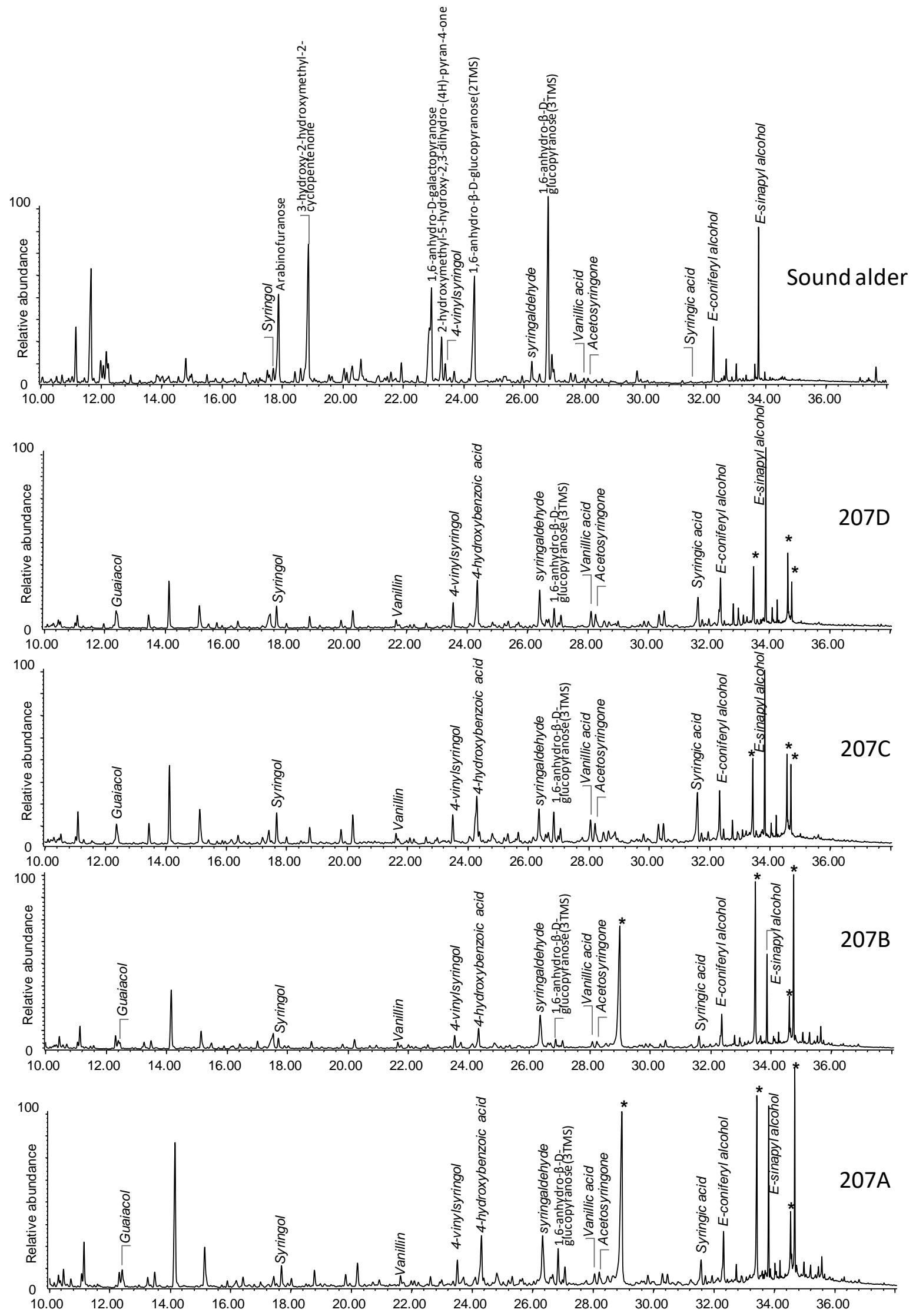

Figure 8 Pyrolysis profiles obtained for samples taken at different depths from the surface of fragment 207 and reference sound alder. Non-italicized: polysaccharide pyrolysis products. In Italics: lignin pyrolysis products, "*”- pyrolysis products derived from linseed oil. 


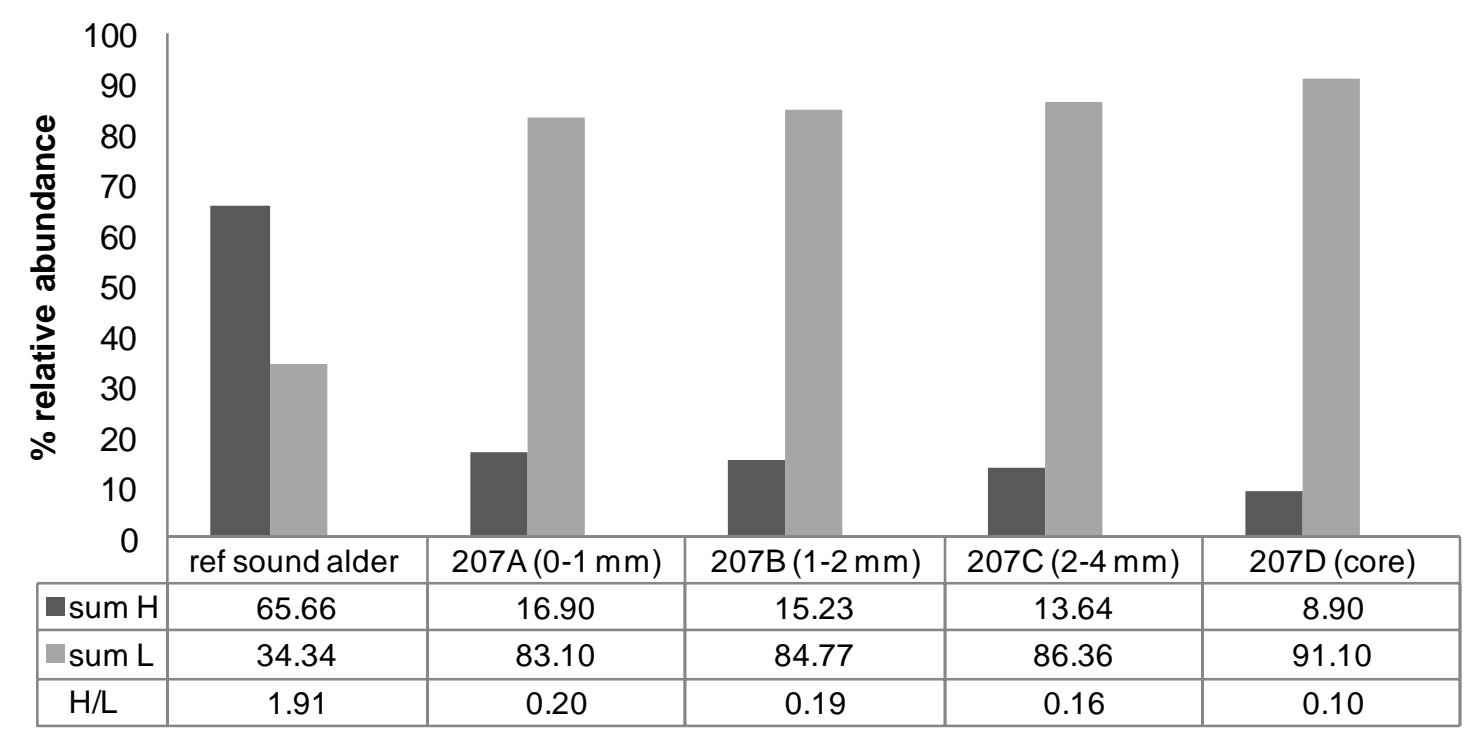

Figure 9 Percentage relative abundances of lignin $(\mathrm{L})$ and holocellulose $(\mathrm{H})$ pyrolysis products.

apersilylated anhydrosugars disilylated anhydrosugars monosilylated anhydrosugars

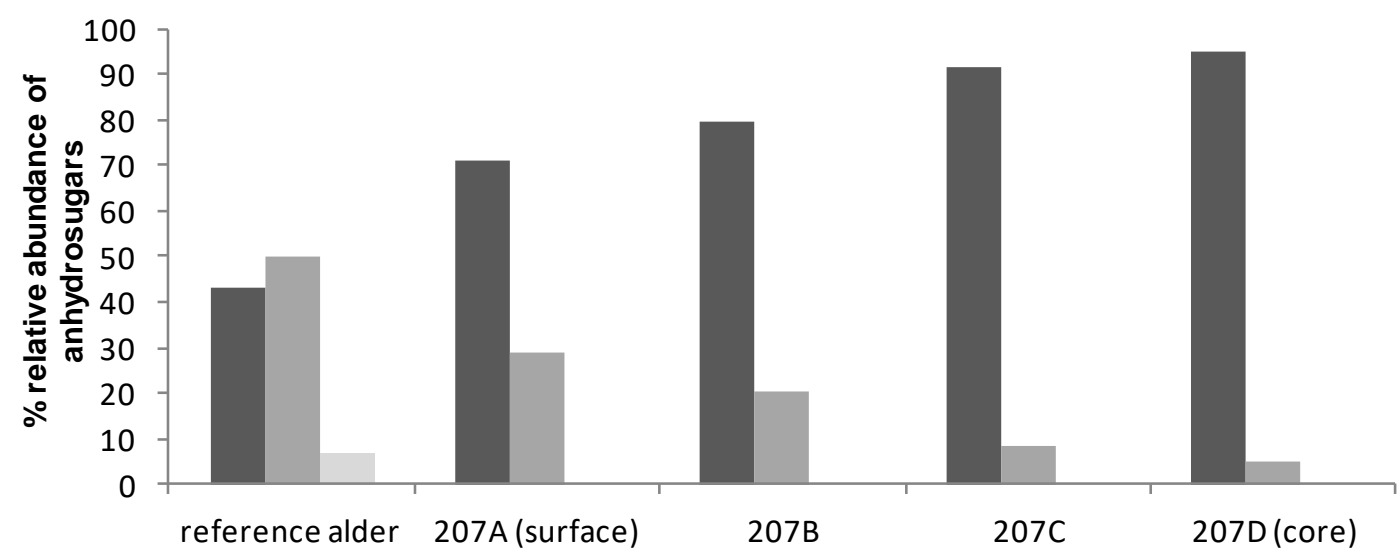

Figure 10 Distribution of anhydrosugars with different degrees of silylation in reference alder and in the archaeological wood samples.

In reference alder wood, the percentage of persilylated (3TMS) anhydrosugars was about $40 \%$. This percentage was higher for all the archaeological samples than for the reference wood. An increase in persilylated anhydrosugars from the surface (about 70\%) to the core (more than 90\%) of the same fragment was observed, indicating a higher degree of holocellulose depolymerisation in the core than in the surface. This confirmed the phenomenon suggested by the $H / L$ ratios: the degradation of polysaccharides in the investigated wood fragment was more extensive in the core than at the surface, which is an opposite trend to that normally observed in archaeological wood artefacts.

In order to obtain information on the alteration of the lignin, we evaluated the various pyrolysis reaction pathways undergone by this biopolymer [30]. Products of primary pyrolytic reaction lead to 
the formation of pyrolysis products corresponding to intact lignin monomers: the two alcohols coniferyl and sinapyl. Modified side chains and/or aromatic rings are formed either during secondary pyrolytic reactions or during wood degradation, producing guaiacyl and syringyl units with altered 3-carbon side chains and shorter side chains (1- or 2-carbon), and demethylated or demethoxylated lignin units [10,34]. These products were sorted into the second lignin category named 'modified side chains'. The third category collects pyrolysis products of oxidized lignin units, such as ketones, aldehydes and acids $[10,11]$.

According to this categorization, the relative sums of the lignin groups were calculated and expressed as percentage abundances with respect to total lignin content. The results are shown in Figure 11.

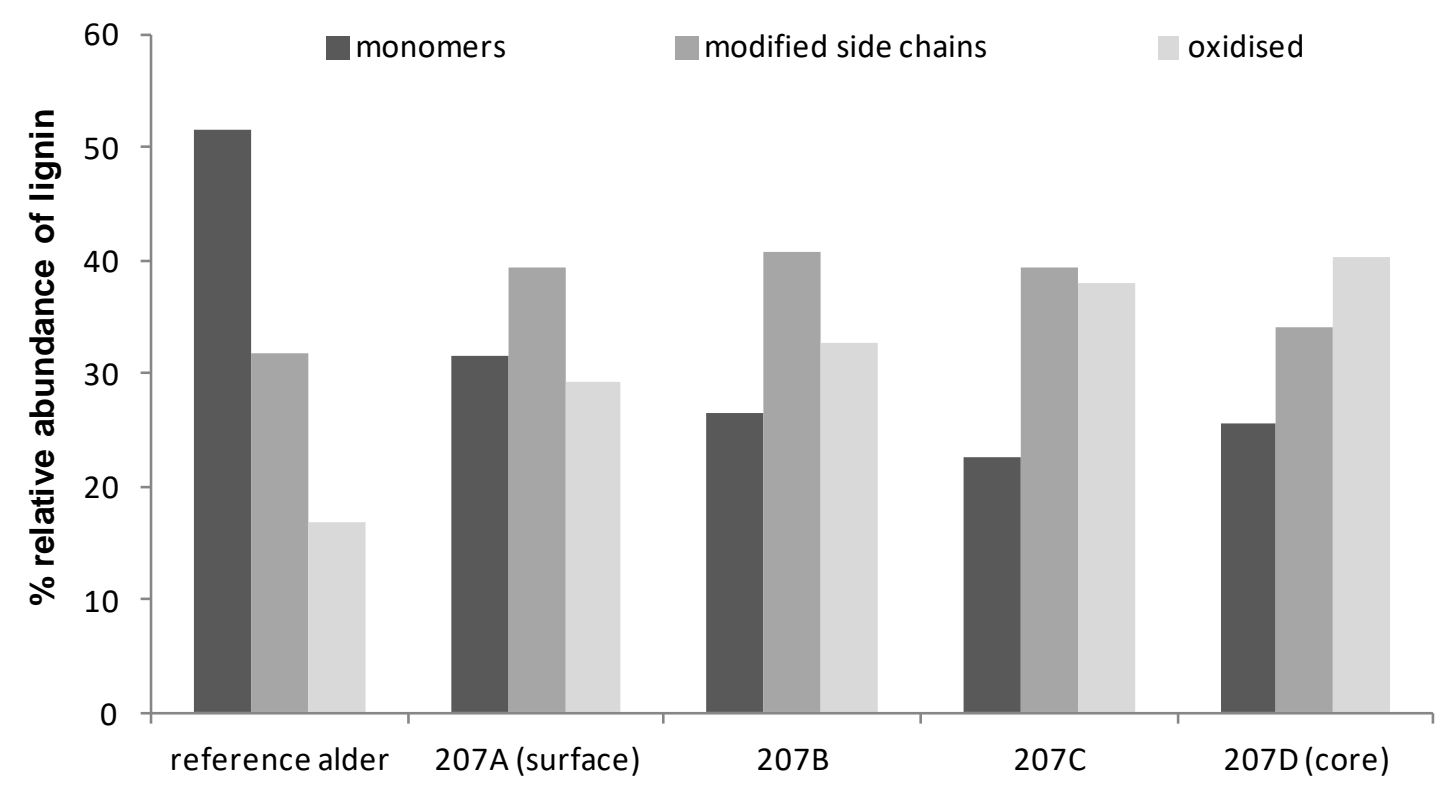

Figure 11 Distribution of the different categories of lignin pyrolysis products, expressed as abundances relative to total lignin content.

The most abundant lignin pyrolysis products in sound wood are the monomers ( $50 \%$ of monomeric structures, coniferyl and sinapyl alcohols), as observed with the alder wood sample. The most notable difference between the archaeological and reference samples was the reduction in monomers in all the archaeological wood samples. Although the monomers in all the archaeological samples collected from fragment 207 were quite abundant, indicating a relatively good preservation of propanoid side chains, the polymer had undergone a partial depolymerisation. This phenomenon is evident from the high content of oxidised lignin pyrolysis products in all the Oseberg samples (29-40\%) with respect to the sound wood (16\%). Similar high degrees of oxidation have already been observed in two other case studies of alum-treated 
Oseberg wood (without linseed oil) and was far more extreme than that found in other examples of archaeological wood (not treated with alum). Thus, the lignin oxidation observed in Oseberg alumtreated woods is related to the alum treatment $[10,11]$.

Comparing the lignin pyrolysis profiles of samples taken at different depths, a lower amount of monomers was observed in the core (207D) than on the surface (207A). This is indicative of the fact that the lignin network is more depolymerised in the core than on the surface. Lignin oxidation was also more evident in the core than on the surface. Again, this is in contrast with the commonly observed pattern of archaeological wood degradation, in which oxidation and depolymerisation phenomena are more evident on the surface than in the core of due to the direct exposure to environmental degradation factors. Thus alum and linseed oil treated wood represent an unusual case study in terms of wood degradation.

\subsection{Analyses of inorganic components}

\subsubsection{XRD}

The XRD patterns of both the sample from the inner core (207-inner) and the outer surface (207outer) showed intense peaks that matched well with reference patterns for $\mathrm{NH}_{4} \mathrm{Al}\left(\mathrm{SO}_{4}\right)_{2} .12 \mathrm{H}_{2} \mathrm{O}$ (tschermigite), also called ammonium alum (Figure 12). The presence of ammonium alum is somewhat surprising, as the information available indicates that objects were treated with potassium alum [35]. We are currently conducting further investigations into this phenomenon.

In 207-outer several small peaks were present in addition to the alum peaks, but their relative intensity was very low and they could not be unambiguously identified. Otherwise the XRD patterns for the inner and outer samples are very similar. Therefore the unusual pattern of wood degradation discussed above cannot be attributed to differences in the crystalline compound composition. 


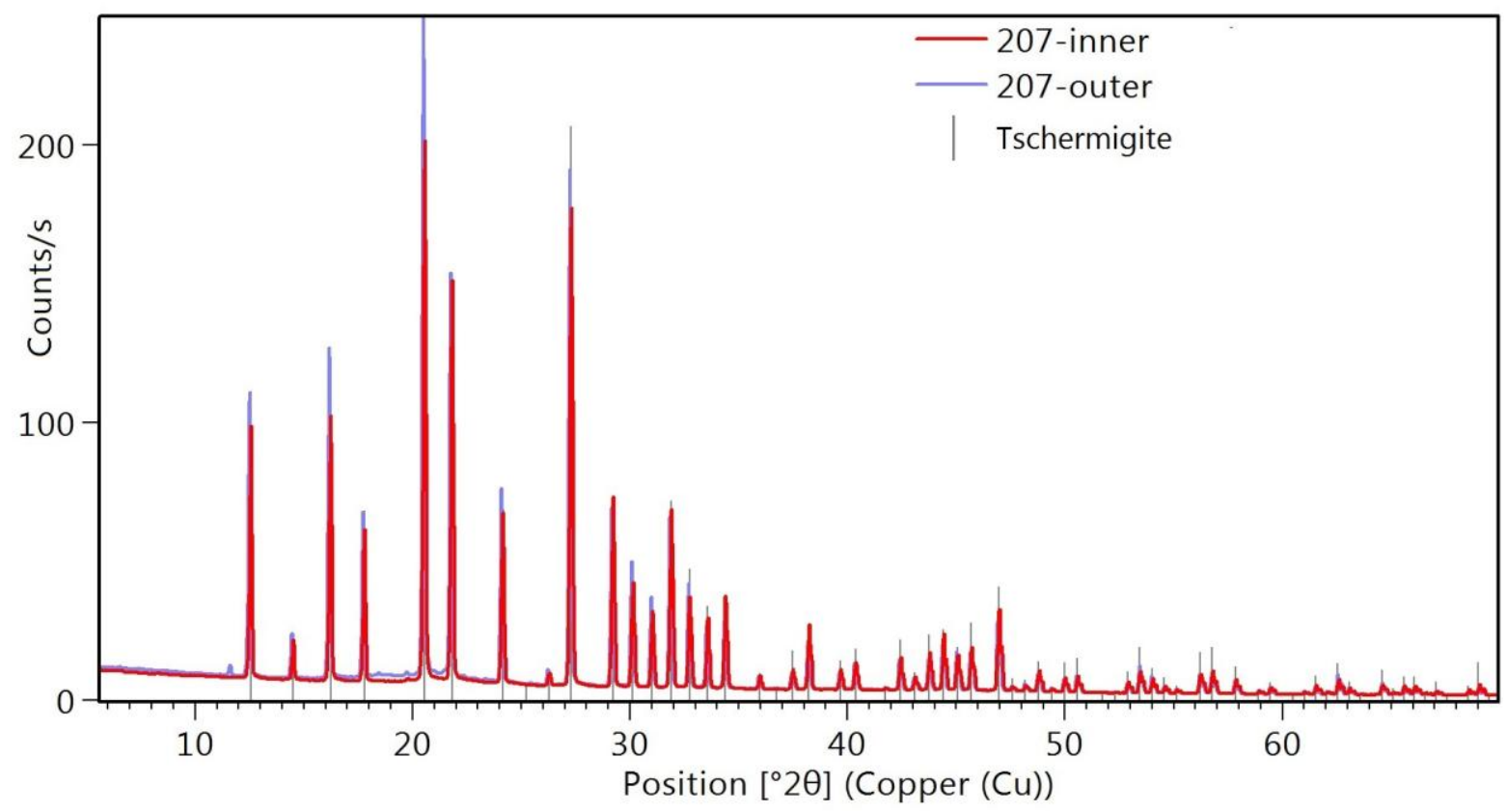

Figure 12. XRD patterns of 207-inner and 207-outer with Tschermigite reference.

\subsubsection{SEM-EDS}

SEM-EDS of 207-inner and 207-outer indicated that S, Al and $\mathrm{K}$ were the major inorganic elements present (Figure 13). Although non-homogeneous, uneven samples such as these are not appropriate for accurate quantitative analysis by SEM-EDS, the spectra indicated that the order of abundance of these elements was $\mathrm{S}>\mathrm{Al}>\mathrm{K}$, in line with the presence of more ammonium alum than potassium alum. Again, the relative abundances were quite similar between the two samples.

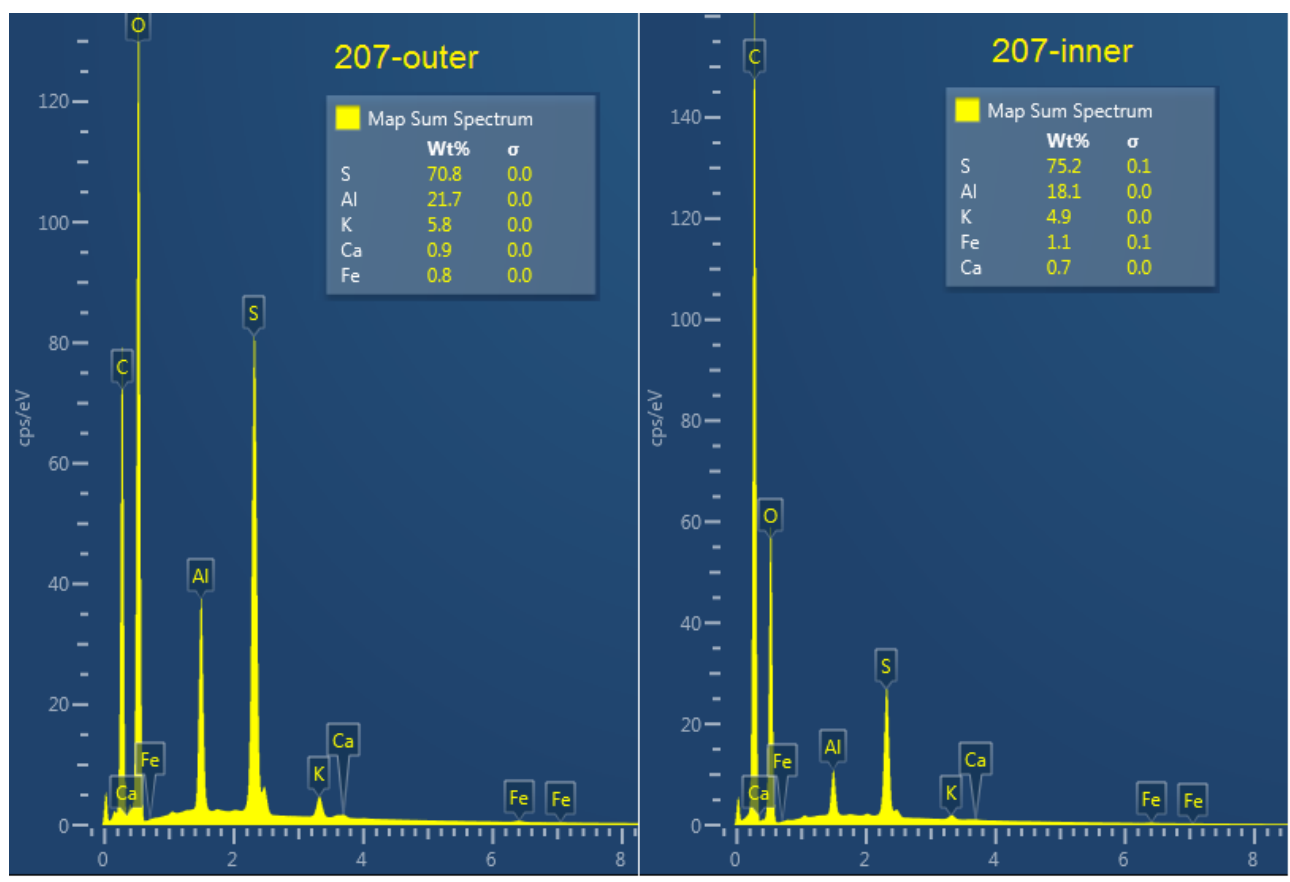

Figure 13 SEM-EDS spectra of 207-outer and 207-inner samples showing S, Al and $\mathrm{K}$ as major inorganic elements. 


\subsubsection{FTIR-spectroscopy}

ATR-FTIR of 207-inner and 207-outer confirmed that ammonium alum was a major component of both samples. The presence of an infrared band around $1440 \mathrm{~cm}^{-1}$, due to an ammonium $\mathrm{NH}$ deformation, differentiated ammonium alum from potassium alum. In 207-outer the ammonium alum absorptions almost completely dominated the spectrum (Figure 14). In 207-inner, lignocellulosic absorptions can also be clearly seen, indicating a significantly lower alum:wood ratio, which was not clear from the XRD analysis. Thus, the core of the fragment can be considered as alum-poor relative to the surface region.

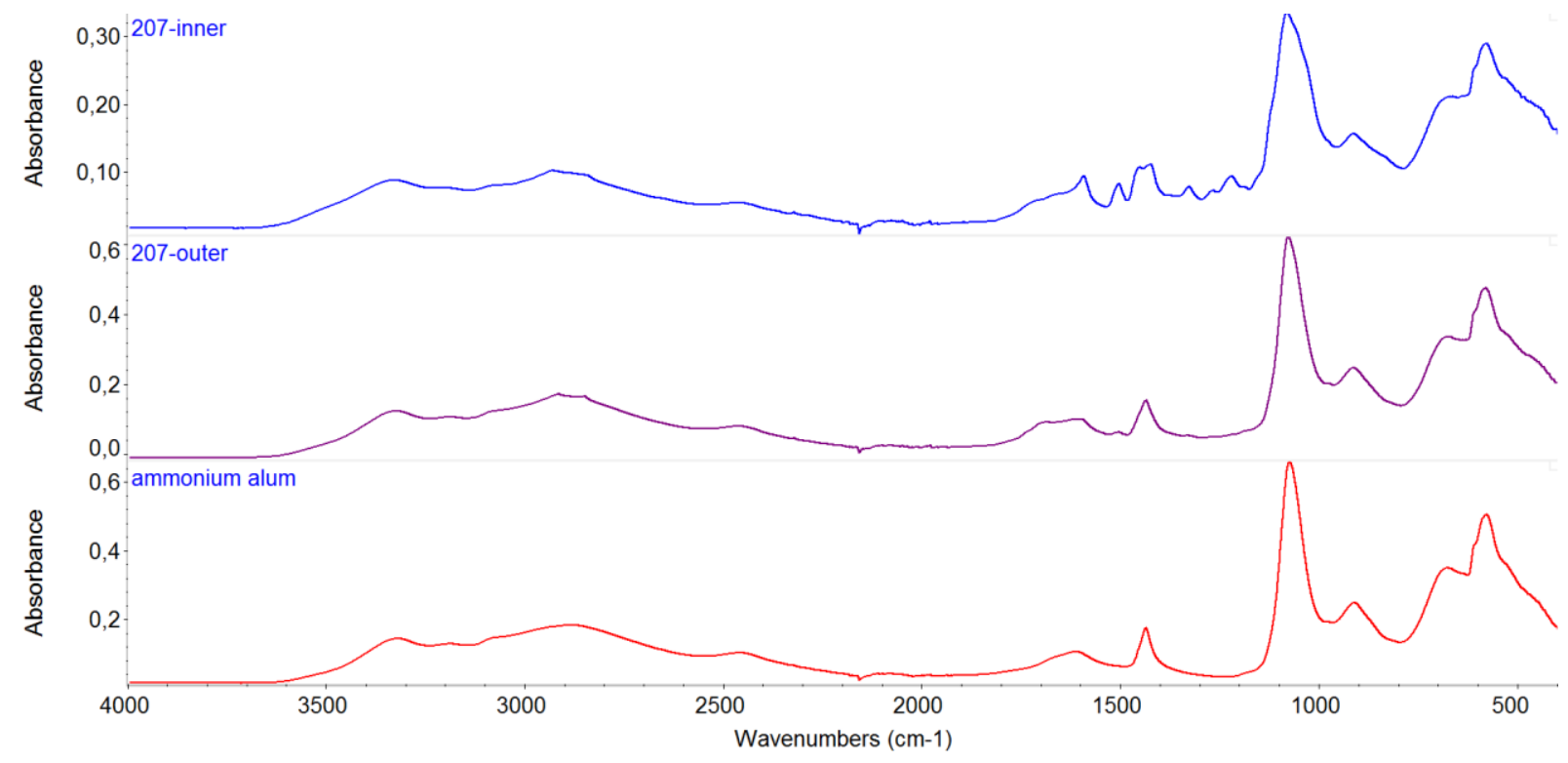

Figure 14 ATR-FTIR spectra of 207-inner and 207-outer with ammonium alum reference.

\section{Conclusions}

A combination of analytical techniques were used to investigate both the organic and inorganic components of archaeological wood treated with alum and linseed oil.

Our multi-analytical approach, based on chromatography and mass spectrometry, enabled the characterization of the different organic materials in treated archaeological wood artifacts, together with the evaluation of the state of oxidation of the wood and of the linseed oil used as a conservation material.

The combination of GC/MS and HPLC-ESI-Q-ToF analysis for the characterization of the lipid profile of linseed oil with Py-GC/MS for the analysis of lignocellulosic polymers enabled us to highlight differences in the degree of oxidation of linseed oil and in the state of decay of lignocellulosic polymers at different depths from the surface of the object.

Both GC/MS and HPLC-ESI-Q-ToF techniques highlighted that, as expected, the linseed oil coating was more oxidized in the surface than in the core of the analysed wood fragment. In fact, 
the sample from the surface showed a higher amount of dicarboxylic acids and oxidized triglycerides than the other samples.

Py-GC/MS showed an opposite trend for the degradation of lignocellulosic polymers, which appeared better conserved at the surface than at the core of the fragment with respect to the other objects from the same collection, which had not been treated with linseed oil. In these latter samples the level of degradation of lignocellulosic polymers was higher at the alum-rich surface than in the alum-poor core. Consequently, the trend of lignin oxidation in the analysed wooden fragment observed by Py-GC/MS, in which the oxidation was more pronounced at the core than at the surface, not only differs from the usual pattern of archaeological wood degradation, but also goes against previously observed correlations between alum and lignin oxidation [6, 7].

The unusual trend does not seem to be correlated to differences in inorganic composition: XRD, SEM-EDS and ATR-FTIR showed that the largest inorganic component of both the surface and core regions was ammonium alum, which was more abundant in the surface than in the core, as would be expected. A possible explanation for the observed wood degradation trend is thus a protective action of linseed oil, which acted as a sacrificial layer undergoing preferential oxidation, efficiently reducing the degradation of lignin and polysaccharides at the surface.

\section{Acknowledgements}

This work was carried out as part of the Saving Oseberg project, funded by the Norwegian Ministry of Education and University of Oslo. SB wishes to thank the scientists at the Paul Scherrer Institute, Switzerland, for facilitating the construction of the X-ray tomographic image shown in Figure 1: Raymund Mokso at the TOMCAT beamline for help with the acquisition of X-ray tomographic data and Anders Kæstner, SINQ for teaching SB how to construct the 3D image. 


\section{References}

[1] N. Bonde, A.E. Christensen, Dendrochronological dating ofthe Viking Age ship burials at Oseberg, Gokstad and Tune, Norway, Antiquity, 67 (1993) 575-583.

[2] A.W. Brøgger, H. Shetelig, H. Falk, Osebergfundet, Distribuert ved Universitetets Oldsaksamling, Oslo, 1917.

[3] A.M. Rosenqvist, The Oseberg Find, its conservation and present state, Colloque sur l'altération du bois - Symposium on the weathering of wood ICOMOS, Ludwigsburg, Allemagne/Germany 8-11 VI 1969, International Council of Monuments and Sites, 1972, pp. 77-87. [4] B.B. Christensen, The Conservation of Waterlogged Wood in the National Museum of Denmark :With a report on the methods chosen for the stabilization of the timbers of the viking ships from Roskilde Fjord, and a report on experiments carried out in order to improve upen these methods, The National Museum of Denmark, Copenhagen, 1970.

[5] S. Braovac, Alum-treated wood. Material characterization. A case study of the Oseberg finds., The Royal Danish Academy of Fine Arts Schools of Architecture, Design and Conservation, Doctoral thesis, Museum of Cultural History, University of Oslo, 2014.

[6] N.A. Lange, Table of Solubilities of Inorganic Compounds in Water at Various Temperatures, in: J.A. Dean (Ed.) Lange'S Handbook of Chemistry, McGraw-Hill, INC, New York, 1999.

[7] S. Braovac, H. Kutzke, The presence of sulfuric acid in alum-conserved wood - Origin and consequences, Journal of Cultural Heritage, 13 (2012) S203-S208.

[8] Y. Fors, H. Grudd, A. Rindby, F. Jalilehvand, M. Sandström, I. Cato, L. Bornmalm, Sulfur and iron accumulation in three marine-archaeological shipwrecks in the Baltic Sea: The Ghost, the Crown and the Sword, Scientific Reports, 4 (2014) 4222.

[9] M. Sandström, F. Jalilehvand, E. Damian, Y. Fors, U. Gelius, M. Jones, M. Salomé, Sulfur accumulation in the timbers of King Henry VIII's warship Mary Rose: A pathway in the sulfur cycle of conservation concern, Proceedings of the National Academy of Sciences of the United States of America, 102 (2005) 14165-14170.

[10] S. Braovac, D. Tamburini, J.J. Łucejko, C. McQueen, H. Kutzke, M.P. Colombini, Chemical analyses of extremely degraded wood using analytical pyrolysis and inductively coupled plasma atomic emission spectroscopy, Microchemical Journal, 124 (2016) 368-379.

[11] C.M.A. McQueen, D. Tamburini, J.J. Łucejko, S. Braovac, F. Gambineri, F. Modugno, M.P. Colombini, $H$. Kutzke, New insights into the degradation processes and influence of the conservation treatment in alum-treated wood from the Oseberg collection, Microchemical Journal, 132 (2017) 119-129.

[12] L. Zoia, D. Tamburini, M. Orlandi, J.J. Łucejko, A. Salanti, E.-L. Tolppa, F. Modugno, M.P. Colombini, Chemical characterisation of the whole plant cell wall of archaeological wood: an integrated approach, Analytical and Bioanalytical Chemistry, (2017) 1-13. 
[13] A.W. Brøgger, H. Shetelig, H. Falk, Osebergfundet, Distribuert ved Universitetets Oldsaksamling, Oslo, 1917.

[14] S. Braovac, Alum-treated wood. Material characterization. A case study of the Oseberg finds, School of Conservation, The Royal Danish Academy of Fine Arts, Schools of Architecture, Design and Conservation, Copenhagen, 2015.

[15] M. Lazzari, O. Chiantore, Drying and oxidative degradation of linseed oil, Polymer Degradation and Stability, 65 (1999) 303-313.

[16] M.P. Colombini, F. Modugno, E. Ribechini, GC/MS in the Characterization of Lipids, in: M.P. Colombini, F. Modugno (Eds.) Organic Mass Spectrometry in Art and Archaeology, Wiley\&Sons Ltd, 2009, pp. 189-213.

[17] J.D.J. van den Berg, K.J. van den Berg, J.J. Boon, Identification of non-cross-linked compounds in methanolic extracts of cured and aged linseed oil-based paint films using gas chromatography-mass spectrometry, Journal of Chromatography, A, 950 (2002) 195-211.

[18] J.D.J. van den Berg, K.J. van den Berg, J.J. Boon, Determination of the degree of hydrolysis of oil paint samples using a two-step derivatisation method and on-column GC/MS, Progress in Organic Coatings, 41 (2001) 143-155.

[19] K. Keune, J.J. Boon, Analytical imaging studies of cross-sections of paintings affected by lead soap aggregate formation, Studies in Conservation, 52 (2007) 161-176.

[20] I. Degano, J. La Nasa, Trends in High Performance Liquid Chromatography for Cultural Heritage, Topics in Current Chemistry, 374 (2016) 20.

[21] D. Tamburini, J.J. Łucejko, F. Modugno, M.P. Colombini, Characterisation of archaeological waterlogged wood from Herculaneum by pyrolysis and mass spectrometry, International Biodeterioration \& Biodegradation, 86, Part B (2014) 142-149.

[22] J. La Nasa, M. Zanaboni, D. Uldanck, I. Degano, F. Modugno, H. Kutzke, E.S. Tveit, B. Topalova-Casadiego, M.P. Colombini, Novel application of liquid chromatography/mass spectrometry for the characterization of drying oils in art: Elucidation on the composition of original paint materials used by Edvard Munch (1863-1944), Analytica Chimica Acta, 896 (2015) 177-189.

[23] L. Blanco-Zubiaguirre, E. Ribechini, I. Degano, J. La Nasa, J.A. Carrero, J. Iñañez, M. Olivares, K. Castro, GC-MS and HPLC-ESI-QToF characterization of organic lipid residues from ceramic vessels used by Basque whalers from 16th to 17th centuries, Microchemical Journal, 137 (2018) 190-203.

[24] J.L. Nasa, I. Degano, E. Ghelardi, F.Modugno, M.P. Colombini, Core shell stationary phases for a novel separation of triglycerides in plant oils by high performance liquid chromatography with electrospray-quadrupole-time of flight mass spectrometer, Journal of Chromatography A, 1308 (2013) 114-124. 
[25] J. La Nasa, I. Degano, F. Modugno, M.P. Colombini, Industrial alkyd resins: characterization of pentaerythritol and phthalic acid esters using integrated mass spectrometry, Rapid Communications in Mass Spectrometry, 29 (2015) 225-237.

[26] J. La Nasa, I. Degano, F. Modugno, M.P. Colombini, Effects of acetic acid vapour on the ageing of alkyd paint layers: Multi-analytical approach for the evaluation of the degradation processes, Polymer Degradation and Stability, 105 (2014) 257-264.

[27] I. Degano, J. La Nasa, E. Ghelardi, F. Modugno, M.P. Colombini, Model study of modern oilbased paint media by triacylglycerol profiling in positive and negative ionization modes, Talanta, 161 (2016) 62-70.

[28] J.J. Łucejko, M. Zborowska, F. Modugno, M.P. Colombini, W. Pradzynski, Analytical pyrolysis vs. classical wet chemical analysis to assess the decay of archaeological waterlogged wood, Analytica Chimica Acta, 745 (2012) 70-77.

[29] J.J. Łucejko, F. Modugno, E. Ribechini, D. Tamburini, M.P. Colombini, Analytical instrumental techniques to study archaeological wood degradation, Applied Spectroscopy Reviews, 50 (2015) 584-625.

[30] D. Tamburini, J.J. Łucejko, M. Zborowska, F. Modugno, W. Prądzyński, M.P. Colombini, Archaeological wood degradation at the site of Biskupin (Poland): wet chemical analysis and evaluation of specific Py-GC/MS profiles, Journal of Analytical and Applied Pyrolysis, 115 (2015) 715.

[31] D. Tamburini, J.J. Łucejko, M. Zborowska, F. Modugno, E. Cantisani, M. Mamoňová, M.P. Colombini, The short-term degradation of cellulosic pulp in lake water and peat soil: A multianalytical study from the micro to the molecular level, International Biodeterioration \& Biodegradation, 116 (2017) 243-259.

[32] R.P. Evershed, Advances in silylation, in: K. Blau, J. Halket (Eds.) Handbook of derivatives for chromatography, John Wiley \& Sons, New York, 1993, pp. 51-100.

[33] D. Fabbri, S. Prati, I. Vassura, G. Chiavari, Off-line pyrolysis/silylation of cellulose and chitin, Journal of Analytical and Applied Pyrolysis, 68-69 (2003) 163-171.

[34] P.F. Van Bergen, I. Poole, T.M.A. Ogilvie, C. Caple, R.P. Evershed, Evidence for demethylation of syringyl moieties in archaeological wood using pyrolysis-gas chromatography/mass spectrometry, Rapid Communications in Mass Spectrometry, 14 (2000) 71 79.

[35] A.M. Rosenqvist, The Stabilizing of Wood Found in the Viking Ship of Oseberg: Part I, Studies in Conservation, 4 (1959) 13-22. 


\section{Figure caption:}

Figure $1 \mathrm{X}$-ray tomographic image showing the typical distribution of alum and linseed oil in a surface sample of one of the Oseberg objects. Alum salts are white/light grey. The linseed oil, which is indistinguishable from the wood fabric, coats fibres and encapsulates alum crystals in most regions. The red circle highlights an area where the linseed oil fills several wood cells. The bar shows 50 microns. Image taken at the TOMCAT beamline, Paul Scherrer Institute, Switzerland.

Figure 2 Trilinolenin, a triglyceride molecule with three linolenyl acyl substituents which is characteristic of linseed oil.

Figure 3 The alum and linseed oil treated fragment, whole (a) and cut into three pieces (b), which also shows that the linseed oil (dark part) did not penetrate the wood fully (light part). The middle piece in (b) was sampled for our analyses. Photo c) shows the depths from the surface for which samples for wood and linseed oil analyses were taken. Samples for inorganic analyses were taken from the surface and from the core only.

Figure 4 Selected ion monitoring (SIM) chromatographic profile of the fatty acid fraction of sample 207A taken 0-1 mm from the surface, after saponification and silylation of carboxylic moieties.

Figure 5 Distribution of fatty acids in samples taken at different depths of fragment 207 and reference sound wood.

Figure 6 HPLC-ESI-Q-ToF extract ion chromatograms of sample 207A taken within 0-1 mm of the surface. L-(18:2) linoleic, O- (18:1) oleic ; P- (16:0) palmitic, S-(18:0) stearic, OxTAGs- oxidized triacylglycerides.

Figure 7 HPLC-ESI-Q-ToF extract ion chromatograms of sample 207D taken from the core of fragment 207. L-(18:2) linoleic, O- (18:1) oleic; P- (16:0) palmitic, S-(18:0) stearic, OxTAGsoxidized triglycerides.

Figure 8 Pyrolysis profiles obtained for samples taken at different depths from the surface of fragment 207 and reference sound alder. Non-italicized: polysaccharide pyrolysis products. In Italics: lignin pyrolysis products, "*”- pyrolysis products derived from linseed oil.

Figure 9 Percentage relative abundances of lignin $(\mathrm{L})$ and holocellulose $(\mathrm{H})$ pyrolysis products.

Figure 10 Distribution of anhydrosugars with different degrees of silylation in reference alder and in the archaeological wood samples.

Figure 11 Distribution of the different categories of lignin pyrolysis products, expressed as abundances relative to total lignin content.

Figure 12. XRD patterns of 207-inner and 207-outer with Tschermigite reference.

Figure 13 SEM-EDS spectra of 207-outer and 207-inner samples showing S, Al and K as major inorganic elements.

Figure 14 ATR-FTIR spectra of 207-inner and 207-outer with ammonium alum reference. 